\title{
Are the Interlaminar Zones of the Ferret Dorsal Lateral Geniculate Nucleus Actually Part of the Perigeniculate Nucleus?
}

\author{
Maria V. Sanchez-Vives, ${ }^{1 a}$ Thierry Bal, ${ }^{2 a}$ Uhnoh Kim, ${ }^{1}$ Marcus von Krosigk, ${ }^{3}$ and David A. McCormick ${ }^{1}$ \\ ${ }^{1}$ Section of Neurobiology, Yale University School of Medicine, New Haven, Connecticut 06510, 2Institut Alfred Fessard, \\ Centre National de la Recherche Scientifique, Gif Sur Yvette Cedex 91198, France, and 3Kinsmen Laboratory of \\ Neurological Research, University of British Columbia, Vancouver, British Columbia, Canada V6T 1 W5
}

The ferret dorsal lateral geniculate nucleus (LGNd) contains interneurons within the interlaminar zones situated between the laminae corresponding to the ipsi- and contralateral eyes. We found that a subset of these neurons exhibits electrophysiological properties similar to those previously reported for perigeniculate (PGN) neurons, including the generation of rhythmic sequences of rebound low-threshold $\mathrm{Ca}^{2+}$ spikes at a frequency of $1-4 \mathrm{~Hz}$ after the intracellular injection of a hyperpolarizing current pulse. These "PGN-like" interlaminar interneurons innervated restricted regions of the A-laminae, inhibited thalamocortical cells through $\mathrm{GABA}_{A}$, and perhaps $\mathrm{GABA}_{B}$, receptors, and were excited by axon collaterals from thalamocortical cells. This reciprocal relationship is identical to that formed by PGN cells and allowed the PGN-like interlaminar neurons to participate in the generation of spindle waves and other network oscillations. Pharmacologically, PGN-like interlaminar interneurons were also similar to PGN neurons: both generated a prolonged depolarization in response to the local application of serotonin, $1 S, 3 R$-ACPD, and CCK8S, and a rapid depolarization followed by a more prolonged hyperpolarization in response to acetylcholine.

Examination of parvalbumin and calbindin staining in the ferret LGNd revealed that both PGN and a subset of interlaminar neurons were parvalbumin-positive. In contrast, calbindinpositive cells were relatively absent in the PGN and sparsely present in the interlaminar zones, but were numerous in the $A$ and $\mathrm{C}$ laminae. Our results indicate that the interlaminar zone in between laminae $A$ and $A 1$ and $A 1$ and $C$ in the ferret LGNd possesses a cell type that is electrophysiologically, pharmacologically, anatomically, immunocytochemically, and functionally similar to neurons in the PGN.

Key words: spindle waves; GABA; thalamus; interneurons; thalamic reticular nucleus; thalamocortical cell collaterals
The dorsal lateral geniculate nucleus (LGNd) of many carnivores is a multilayer structure consisting of bands (laminae) of neurons that are characterized by their retinal innervation and receptivefield properties (Guillery, 1970; Sanderson, 1974; Stryker and Zahs, 1983). In between each of these laminae of thalamocortical neurons are the interlaminar zones. Neurons immunoreactive for the presence of GABA or the synthesizing enzyme glutamic acid decarboxylase (GAD) in or adjacent to the cat LGNd can be subdivided into at least three distinct categories based on the location of their cell body: intralaminar, interlaminar, and perigeniculate (Montero, 1989a). Previous studies have examined in detail the electrophysiological, pharmacological, and anatomical properties of intralaminar and perigeniculate (PGN) GABAergic neurons and have found marked differences between these two cell types. For example, PGN neurons generate rhythmic bursts of action potentials at resting membrane potentials and tonic, singlespike activity after depolarization (Avanzini et al., 1989; Hu et al.,

\footnotetext{
Received May 22, 1996; revised July 1, 1996; accepted July 8, 1996.

This research was supported by grants from National Institutes of Health, the Klingenstein Fund, the Sloan Foundation, and the Medical Research Council. M.V.S.V. is a fellow of NATO and the Epilepsy Foundation of America. We thank Françoise Bal for her assistance in the camera lucida reconstruction of neurons, Anita Luthi for her comments on this manuscript, and Kendall Lee for his contribution. The original data included in the manuscript and a program for viewing and analyzing this data are located at the following web site: http://info.med.yale.edu/neurobio/mccormick/mccormick.

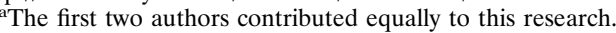

Correspondence should be addressed to Dr. David A. McCormick, Section of Neurobiology, Yale University School of Medicine, New Haven, CT 06510.

Copyright (C) 1996 Society for Neuroscience $0270-6474 / 96 / 165923-19 \$ 05.00 / 0$
}

1989; Bal and McCormick, 1993; Bal et al., 1995b), are densely innervated by axon collaterals of thalamocortical neurons (Ferster and Levay, 1978; Friedlander et al., 1981; Ide, 1982; Montero and Singer, 1984; Montero, 1989b; Bal et al., 1995a), can have large, binocular receptive fields (Sanderson, 1971; Dubin and Cleland, 1977; So and Shapley, 1981; Uhlrich et al., 1991; Jones and Sillito, 1994), do not appear to be innervated by afferents from the retina (Guillery, 1970), are strongly excited by serotonin (5-HT) and noradrenaline (McCormick and Wang, 1991), and are excited and then inhibited through the activation of nicotinic and muscarinic receptors by acetylcholine (ACh) (Lee and McCormick, 1995). In comparison, GABAergic neurons within the relay laminae of the cat LGNd typically do not intrinsically generate rhythmic bursts of action potentials (Pape and McCormick, 1995), are not strongly innervated by thalamocortical cells (Montero, 1991; Bal et al., 1995a), typically have small, monocular receptive fields (Friedlander et al., 1981), are directly innervated by the retina (Hamos et al., 1985; Montero, 1991), are not strongly excited by 5 -HT or noradrenaline (Pape and McCormick, 1995), and exhibit inhibitory but not excitatory responses to ACh (McCormick and Pape, 1988; Pape and McCormick, 1995). These results suggest that different types of GABAergic neuron within the relay nuclei of the thalamus perform markedly distinct functions in the operation of local circuits. The intralaminar interneurons appear to be involved in the generation or modification of the fine receptive-field structure of thalamocortical cells (for review, see Norton and Godwin, 1992), whereas the PGN appears to be strongly involved in the state-dependent generation of intrathalamic synchronized 
activity (Hu et al., 1989; Bal et al., 1995a,b) and the generation of more global receptive-field properties (see Jones and Sillito, 1994).

The role of the GABAergic neurons located in the interlaminar zone in the function of the LGNd is unknown. Electron microscopic examination of synaptic profiles on interlaminar zone GABAergic neurons reveals that these cells may receive strong innervation from thalamocortical cells, cortical cells, and other GABAergic neurons, similar to PGN cells (Montero, 1989a). Based on these results, Montero has speculated that some of the GABAergic neurons in the interlaminar zones may function in a manner similar to PGN cells (Montero, 1989a). Indeed, examination of the dendritic arbors of interlaminar interneurons reveals that some of these run parallel to the interlaminar zone in which they lie (O'Leary, 1940; Montero, 1989a), similar to the dendritic arbors of PGN cells (Szentágothai, 1972; Uhlrich et al., 1991). In addition, previous extracellular recordings in the cat LGNd have shown that binocularly responsive cells are restricted to both the interlaminar zones and the PGN (Kozak et al., 1965; Sanderson, 1971; Xue et al., 1988). Together, these results suggest that a subset of GABAergic neurons within the interlaminar zone of the cat LGNd may function in a manner similar to perigeniculate neurons. Here we tested this hypothesis in the ferret LGNd by examining the electrophysiological, pharmacological, and morphological features, as well as the functional connectivity, of interlaminar interneurons.

\section{MATERIALS AND METHODS}

For the preparation of slices, male or female ferrets, $\sim 2-4$ months old, were deeply anesthetized with sodium pentobarbital $(30 \mathrm{mg} / \mathrm{kg})$ and killed by decapitation. The forebrain was rapidly removed, and the hemispheres were separated with a midline incision. Sagittal slices (400 $\mu \mathrm{m}$ thick) were formed on a vibratome (Ted Pella, Inc.). A modification of the technique developed by Aghajanian and Rasmussen (1989) was used to increase tissue viability. During preparation of slices, the tissue was placed in a solution in which $\mathrm{NaCl}$ was replaced with sucrose while maintaining an osmolarity of $307 \mathrm{mOsm}$. After preparation, slices were placed in an interface-style recording chamber (Fine Sciences Tools) and allowed at least $2 \mathrm{hr}$ to recover. The bathing medium contained (in $\mathrm{mM}$ ): $\mathrm{NaCl} 124, \mathrm{KCl} 2.5, \mathrm{MgSO}_{4} 1.2, \mathrm{NaH}_{2} \mathrm{PO}_{4} 1.25, \mathrm{CaCl}_{2} 2, \mathrm{NaHCO}_{3} 26$, dextrose 10 , and was aerated with $95 \% \mathrm{O}_{2} / 5 \% \mathrm{CO}_{2}$ to a final $\mathrm{pH}$ of 7.4. For the first $20 \mathrm{~min}$ that the geniculate slices were in the recording chamber, the bathing medium contained an equal mixture of the normal $\mathrm{NaCl}$ and the sucrose-substituted solutions. Bath temperature was maintained at $34-35^{\circ} \mathrm{C}$.

Intracellular recording electrodes were formed on a Sutter Instruments P-80 micropipette puller from medium-walled glass (WPI, 1BF100) and beveled on a Sutter Instruments beveler. Micropipettes were filled with $1.2 \mathrm{~m} \mathrm{~K}$-acetate and $2 \%$ biocytin for intracellular labeling of recorded neurons and had resistances of between 60 and $100 \mathrm{M} \Omega$. Cells were included in the present study if they exhibited a stable resting membrane potential for at least $10 \mathrm{~min}$ (typically $45-90 \mathrm{~min}$ ), were able to generate a repetitive barrage of action potentials after depolarization, exhibited input resistances of at least $30 \mathrm{M} \Omega$, and the intracellular recording electrode entered the slice in or adjacent to the interlaminar zones. The interlaminar zones between laminae A and A1 and between A1 and C were readily visible with epi-illumination of the living geniculate slice. Biocytin-filled neurons were visualized through standard avidin-biotinhorseradish peroxidase reaction with diaminobenzidine (Horikawa and Armstrong, 1988). Neurons were reconstructed using camera lucida with 40,60 , or $100 \times$ objectives. Extracellular recordings were obtained with low-resistance $(<1 \mathrm{M} \Omega)$ tungsten microelectrodes (Frederick Haer Corporation) placed either in the A-laminae or in the PGN and band pass-filtered between $\sim 300$ and $10,000 \mathrm{~Hz}$.

Drugs were applied with the pressure-pulse technique in which the delivery of a brief pulse of nitrogen $(10-100 \mathrm{msec}, 200-350 \mathrm{kPa})$ was applied to the micropipette to extrude volumes of 2-20 pl. Application of glutamate was performed at varying locations and depths within the slice to determine the best response. Other agonists and antagonists were applied to the surface of the slice either within $50 \mu \mathrm{m}$ of the entry point of the recording electrode or as indicated in the figures. The latency for activation of neurons with local application of glutamate was estimated by performing extracellular multiple-unit recordings adjacent to the glutamate-applying micropipette within the slice. These applications revealed that pressure-pulse application of glutamate resulted in the activation of action potentials at a minimum latency of $20-25 \mathrm{msec}$, followed by an increase in the intensity of neuronal discharge peaking at $\sim 35-40$ msec. Therefore, monosynaptic connections between neurons excited by local application of glutamate and recipient cells will have a minimum latency of 20-30 msec. This latency may be longer if the location of the excited neuron is not immediately adjacent to the local application of glutamate. The detection of monosynaptic connections was facilitated by the relative lack of polysynaptic excitatory connections between thalamocortical cells in the LGNd.

Parvalbumin and calbindin immunocytochemistry was performed to examine the distribution of neurons positive for these $\mathrm{Ca}^{2+}$-binding proteins. Ferrets (2-3 months old) were deeply anesthetized with intraperitoneal injections of sodium pentobarbital $(40 \mathrm{mg} / \mathrm{kg})$ and perfused through the heart briefly with $0.85 \%$ sodium chloride in $10 \mathrm{~mm}$ PB followed by $4 \%$ paraformaldehyde in $0.1 \mathrm{~m}$ sodium phosphate buffer, $\mathrm{pH}$ 7.2. After the brains were removed from the skull, they were post-fixed overnight at $4{ }^{\circ} \mathrm{C}$ in $4 \%$ paraformaldehyde and $20 \%$ sucrose. The brains were cut into $20-\mu \mathrm{m}$-thick sections with a freezing microtome. The sections were incubated with gentle agitation for $48-72 \mathrm{hr}$ at $4^{\circ} \mathrm{C}$ with monoclonal anti-parvalbumin or anti-calbindin (Sigma, St Louis, MO) diluted 1:500 or 1:200, respectively, in PBS containing $1 \%$ normal goat serum and $0.3 \%$ Triton X-100. After the sections were rinsed three times with PBS, they were incubated for $1 \mathrm{hr}$ at room temperature with biotinylated goat anti-mouse Ig diluted 1:100 in PBS containing 1\% normal goat serum. The sections were rinsed and incubated in a 1:50 dilution of avidin-biotin complex (Vectastain Elite, Vector Laboratories, Burlingame, CA) for $1 \mathrm{hr}$. After being rinsed, the sections were processed with $3.3^{\prime}$-diaminobenzidine (DAB), coverslipped, and photographed. Adjacent sections were processed for parvalbumin, calbindin, and Nissl bodies. In addition, immunocytochemical labeling of GABA was also performed on some sections (Schwartz and Meineke, 1992). Measurements are presented as mean $\pm \mathrm{SD}$.

\section{RESULTS}

Intracellular recording from neurons in sagittal slices of the ferret LGNd maintained in vitro in which the microelectrode was within or adjacent to the interlaminar zones revealed four electrophysiologically distinct cell types. The most prominent cell type exhibited electrophysiological features previously associated with thalamocortical neurons (Fig. 1A) (Jahnsen and Llinás, 1984a,b); indeed, when the morphology of these cells was recovered, they exhibited morphological features typical for thalamocortical neurons and their cell bodies were found to be either within the interlaminar zones or on the edge of the relay laminae. Three additional cell types were associated with interneurons. The first exhibited electrophysiological properties that have been reported previously for interneurons whose cell bodies lie within the A or A1 laminae of the cat LGNd (McCormick and Pape, 1988; Pape and McCormick, 1995). These electrophysiological features include the generation of relatively short-duration $(0.27 \pm 0.14$ msec at half-amplitude) action potentials and the relative lack of pronounced rebound $\mathrm{Ca}^{2+}$ spikes after hyperpolarization (Fig. $1 B)$. In addition to recording these cells in or adjacent to the interlaminar zones, we also found these cells within the A laminae, as in previous recordings (Pape and McCormick, 1995) and, therefore, we refer to these cells as intralaminar interneurons. Intracellular injection of biocytin revealed in two of the intralaminar interneurons that these cells were on the border between the A laminae and the interlaminar zone (not shown).

A third category of neuron exhibited electrophysiological features that have been associated previously with neurons in the perigeniculate nucleus or the thalamic reticular nucleus $(n=15)$ (Mulle et al., 1986; Avanzini et al., 1989; Bal et al., 1993; Contreras et al., 1993). These neurons were recorded only within or 
A Thalamocortical relay neuron
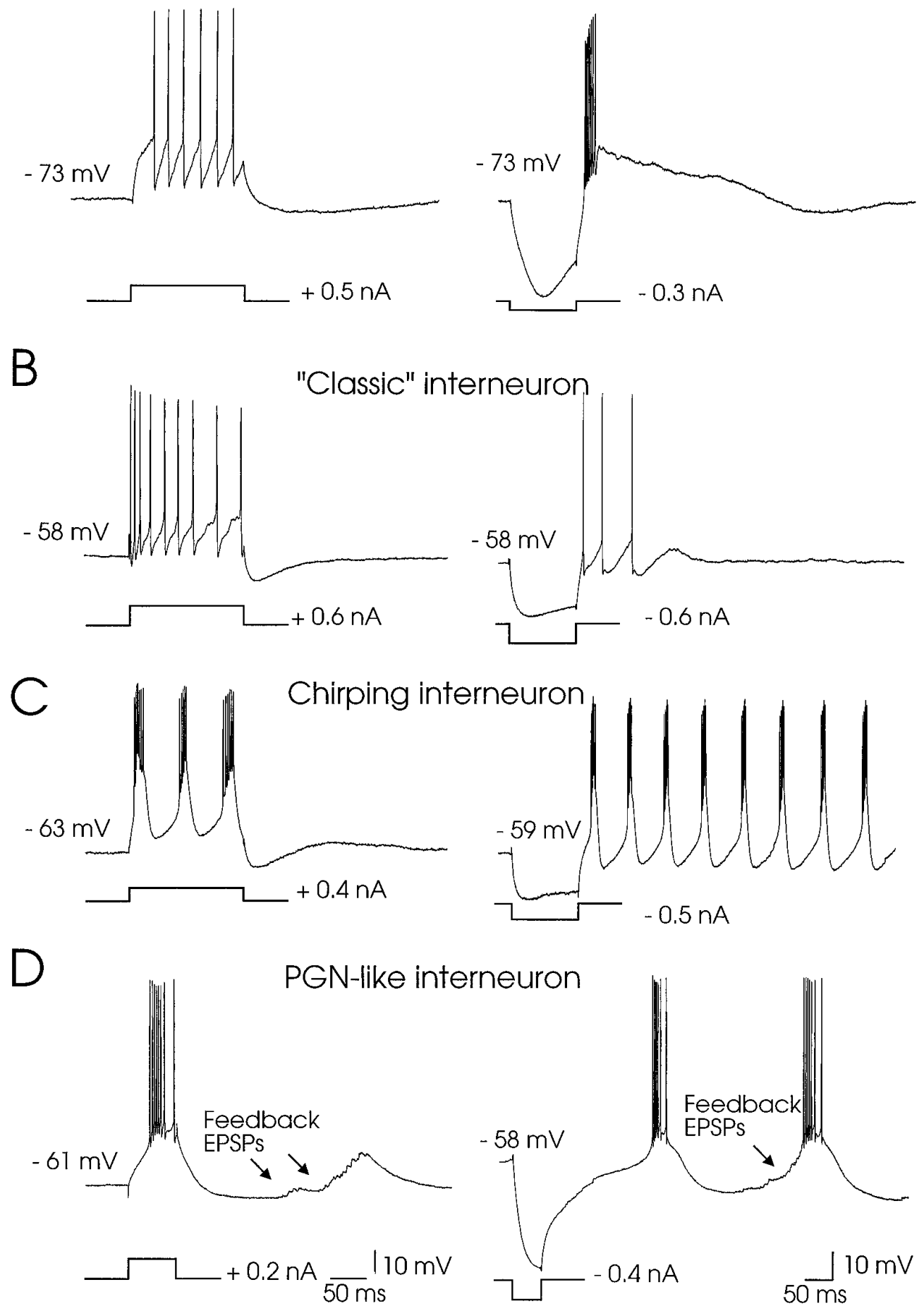

Figure 1. Four electrophysiologically distinct types of neurons were recorded in or adjacent to the interlaminar zones. $A$, Thalamocortical neurons generated a train of action potentials, with a delayed onset, in response to depolarization and a rebound burst of action potentials after hyperpolarization. These cells also exhibited a strong "sag" in the electrotonic response to hyperpolarization. $B$, "Classic" interneurons exhibited a train of action potentials in response to a depolarizing current pulse and a rebound response of one or a few action potentials in response to a hyperpolarizing current pulse. These interneurons were recorded throughout the laminae and within the interlaminar zones. $C$, "Chirping" interneurons generated repetitive burst discharges at $10-15 \mathrm{~Hz}$ in response to depolarizing or as a rebound response to hyperpolarizing current pulses. So far these neurons have only been recorded in or adjacent to the interlaminar regions of the LGNd. $D$, PGN-like interneurons exhibited a burst of action potentials in response to depolarization from a membrane potential of -61 to -70 $\mathrm{mV}$ and a rhythmic sequence of rebound bursts after hyperpolarization from a more depolarized membrane potential $(-58 \mathrm{mV})$. These cells also exhibited "Feedback EPSPs" (arrows) after the generation of action potential bursts. PGN-like interneurons were recorded only in, or immediately adjacent to, the interlaminar zones. The data for this and other figures are available at http://info.med.yale.edu/ neurobio/mccormick/mccormick. adjacent to the interlaminar zones between the $\mathrm{A}$ and $\mathrm{A} 1$, and $\mathrm{A} 1$ and $\mathrm{C}$, laminae, and morphological reconstruction of these cells (see below) revealed that their cell bodies lie within or adjacent to these interlaminar zones. Because of the similarity of their electrophysiological properties to perigeniculate cells, we refer to these interneurons as "PGN-like" interlaminar interneurons. The electrophysiological properties of these interlaminar interneurons include the generation of relatively short-duration action potentials and robust rebound low-threshold $\mathrm{Ca}^{2+}$ spikes that were followed by pronounced afterhyperpolarizations and could occur in rhythmic sequences at around $1-4 \mathrm{~Hz}$ (Fig. 1D).

Finally, on rare occasions, an additional type of interneuron was recorded that was distinct from the other categories $(n=$ $6)$. These neurons also exhibited relatively short-duration action potentials $(0.28-0.32 \mathrm{msec}$ at half-amplitude) as did the other two types of interneurons, but were distinct in that these cells generated rhythmic bursts of action potentials at frequencies of $12-15 \mathrm{~Hz}$ after the intracellular injection of a hyperpo- 
A

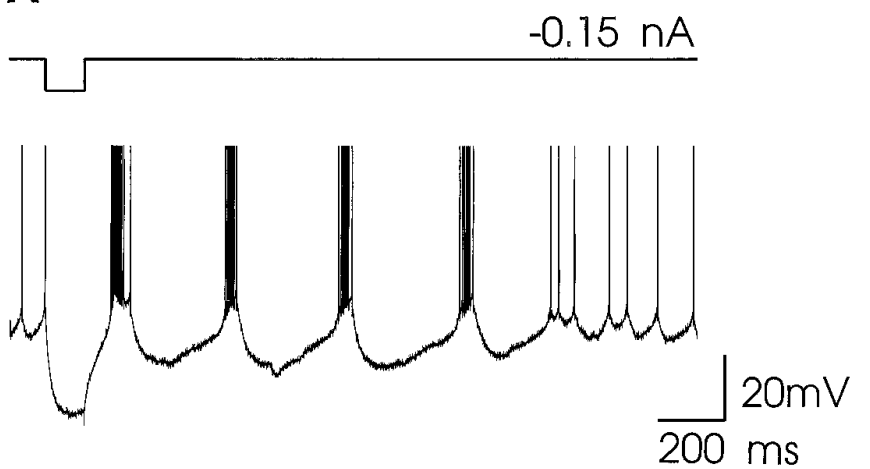

B
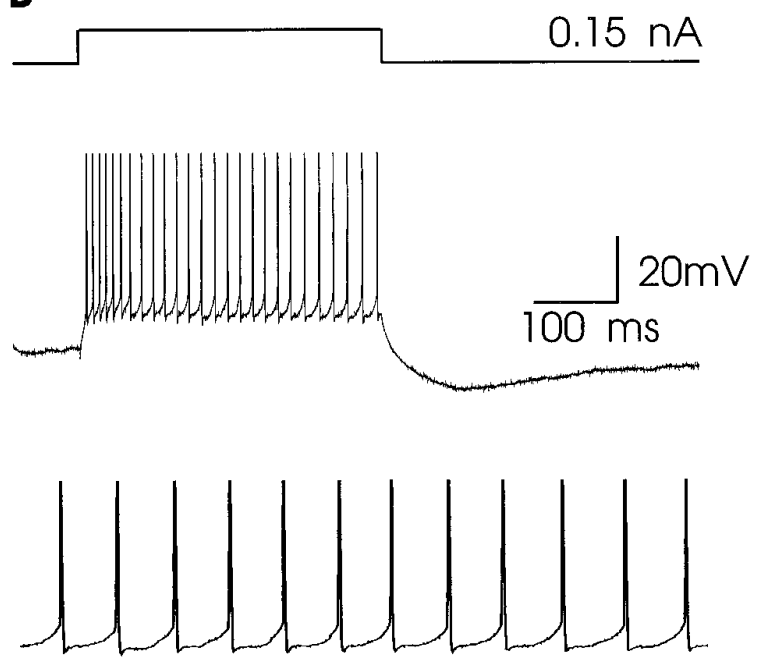
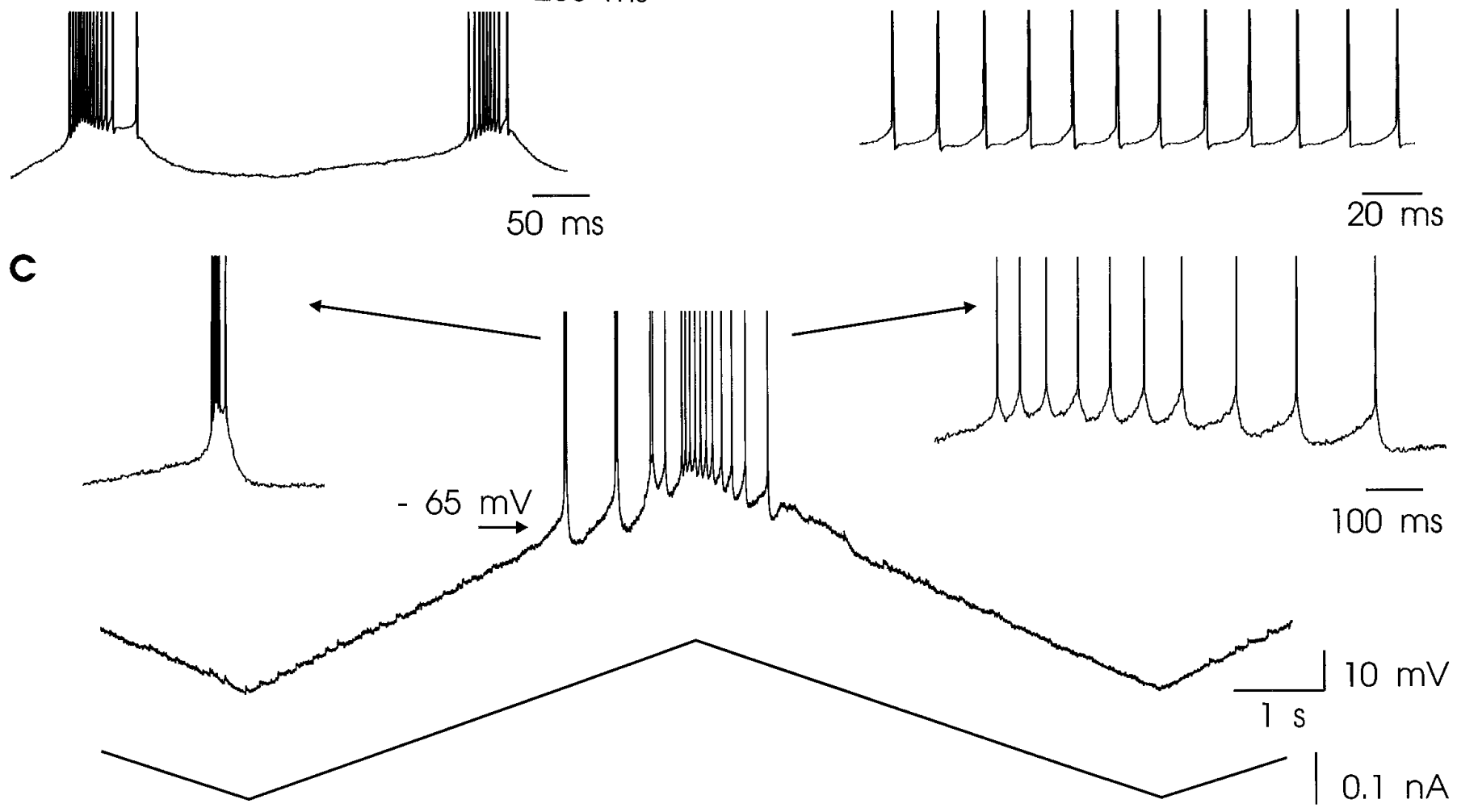

Figure 2. Electrophysiological properties of PGN-like interlaminar cells. $A$, Intracellular injection of a hyperpolarizing current pulse after depolarization of the neuron into the single-spike firing mode with the injection of d.c. results in the generation of a rhythmic sequence of burst discharges that are interspaced by hyperpolarizing potentials. The first and second bursts are expanded for detail. In $B$, intracellular injection of a depolarizing current pulse results in the generation of a train of action potentials. A portion of the tonic firing is expanded for detail. In $B$, intracellular injection of a slowly depolarizing and hyperpolarizing current ramp illustrates the two firing modes of PGN-like interlaminar neurons. At a threshold of approximately -65 $\mathrm{mV}$, the cell generates a low-threshold spike and burst of action potentials. This is followed by a rhythmic sequence of two additional low-threshold bursts. Further depolarization switches the neuron into the single-spike mode of action potential generation, the frequency of which is related to the intensity of the current injection.

larizing or depolarizing current pulses (Fig. 1C). In addition, the frequency of action potential generation within each of these bursts was unusually high, within the range of $600-750$ Hz. Here we refer to these cells as "chirping" interneurons because of the unusual sound of their repetitive burst discharges over the audio monitor. Chirping interneurons were found only when the recording electrode appeared to be in the interlaminar zones and the intracellular injection of biocytin into these cells revealed on two occasions cell bodies that were within or adjacent to the interlaminar zones. In the present report, we focus on the electrophysiological, morphological, and interactions with thalamocortical neurons of the PGN-like interlaminar interneurons.

\section{Electrophysiological properties of PGN-like interlaminar interneurons}

Intracellular injection of depolarizing and hyperpolarizing current pulses as well as a slowly depolarizing and hyperpolarizing ramp of current into the PGN-like interlaminar interneurons revealed that these cells possess two distinct modes of action potential generation (Fig. 2). Tonic depolarization of these neurons positive to approximately -55 to $-52 \mathrm{mV}$ resulted in the generation of trains of action potentials (Fig. $2 B, C$ ). Intracellular injection of a hyperpolarizing current pulse at these depolarized membrane potentials resulted in the generation of a rebound burst of action potentials that was followed by an afterhyperpolarization and additional rebound bursts of action potentials (Fig. $2 A$ ). The 
intercalation of the afterhyperpolarizing potentials and the rebound bursts of action potentials gave rise to a rhythmic sequence of burst discharges at frequencies of 1-4 Hz. Interestingly, within each burst of action potentials, the frequency of action potential generation exhibited a clear increase followed by a decrease in frequency in an "accelerando-decelerando" pattern (Fig. 2A), similar to that which has been associated previously with burst firing in thalamic reticular or PGN neurons, but not in thalamocortical cells (Domich et al., 1986; Hu et al., 1989). The amplitude-time course and voltage dependence of the slow spikes underlying the bursts of action potentials suggest that they are lowthreshold $\mathrm{Ca}^{2+}$ spikes. Indeed, intracellular injection of current pulses that progressively increased either in amplitude or duration resulted in a progressive increase in amplitude of these rebound events, as expected for low-threshold $\mathrm{Ca}^{2+}$ spikes (Jahnsen and Llinás, 1984a,b).

Intracellular injection of a slowly depolarizing and hyperpolarizing current ramp illustrated well the two different firing modes (Fig. 2C). Slowly depolarizing PGN-like interlaminar neurons resulted in the activation of a rhythmic burst of action potentials at membrane potentials of approximately -65 to $-60 \mathrm{mV}$ (Fig. $2 C)$. Further depolarization typically switched the neuron to the tonic firing mode of action potential generation in which the frequency of firing appeared to be more or less linearly related to the degree of depolarization (Fig. $2 C$ ). The two firing modes were separated by only a few millivolts (Fig. $2 C$ ). Progressive hyperpolarization of interlaminar interneurons resulted in a relatively linear membrane response, without the presence of strong, slow, time-dependent rectification of the membrane potential (Fig. 2C). Intracellular recording from a representative sample of 9 PGNlike interlaminar interneurons revealed an average resting membrane potential of $-71 \pm 6.4 \mathrm{mV}$, an average spike amplitude of $83 \pm 10.3 \mathrm{mV}$, and an average spike width (at half-amplitude) of $0.33 \pm 0.05 \mathrm{msec}$.

\section{Functional connectivity of interlaminar interneurons}

We have reported previously that sagittal slices of the ferret LGNd spontaneously generate spindle waves at the rate of approximately one every 5-20 sec (von Krosigk et al., 1993; Bal et al., 1995a,b). Intracellular recordings from PGN-like interlaminar interneurons during the generation of spindle waves revealed that these cells receive barrages of PSPs in synchrony with burst firing in the A laminae of the LGNd (Fig. $3 A, B$ ). These PSPs were depolarizing at all membrane potentials examined $(-100$ to -50 $\mathrm{mV}$ ) and were excitatory in that they could result in the generation of either low-threshold $\mathrm{Ca}^{2+}$ spikes or, after tonic depolarization with the intracellular injection of d.c., the activation of fast $\mathrm{Na}^{+} / \mathrm{K}^{+}$action potentials. When PGN-like interlaminar interneurons were at normal resting membrane potentials of -60 to -75 $\mathrm{mV}$, they exhibited progressive hyperpolarization during the generation of each spindle wave (Fig. $3 A$ ), similar to PGN neurons (Bal et al., 1995b).

Close examination of the fast EPSPs arriving in PGN-like interlaminar interneurons during the generation of spindle waves (or when glutamate was applied to the A laminae) revealed that individual EPSPs were 0.7 to $4.2 \mathrm{mV}(2.26 \pm 1.06 \mathrm{mV} ; n=50$ in 1 cell) in amplitude at membrane potentials of -65 to $-90 \mathrm{mV}$ (for example, see Fig. 3). That these EPSPs were generated by burst firing in neighboring thalamocortical neurons is suggested by several findings. First, the barrages of EPSPs occurring during the generation of spindle waves were synchronized with multipleunit activity in the A laminae of the LGNd (Fig. 3B). Second, the
EPSP barrages often arrived in clusters of 2-5 at frequencies of $125-280 \mathrm{~Hz}$ in a manner similar to burst firing in thalamocortical neurons (Fig. 4). Finally, the other known sources of excitation to neurons of the LGNd, the retina and cerebral cortex, are not present in the geniculate slice.

We have demonstrated previously that bath application of the $\mathrm{GABA}_{\mathrm{A}}$ receptor antagonist bicuculline transforms normal spindle waves into marked 2-3 Hz synchronized paroxysmal oscillations (von Krosigk et al., 1993; Bal et al., 1995a,b). During the generation of these bicuculline-induced "seizure-like" oscillations, PGN neurons generate strong bursts of up to 60 action potentials at frequencies of up to $500 \mathrm{~Hz}$ with each cycle (von Krosigk et al., 1993; Bal et al., 1995b). Similarly, bath application of bicuculline methiodide $(20 \mu \mathrm{M})$ during the intracellular recording from a PGN-like interlaminar interneuron also resulted in a transformation of normal spindle waves into seizure-like events (Fig. 3C,D). This transformation of the network oscillation from 5-10 to $3-4 \mathrm{~Hz}$ was associated with a large increase in the frequency and number of action potentials generated in the interlaminar interneuron (Fig. $3 B, D$ ). The bursts of action potentials generated increased from $4-8$ at frequencies of up to $250 \mathrm{~Hz}$ per burst during the generation of a spindle wave to 20-30 spikes at frequencies of up to $425 \mathrm{~Hz}$ per burst during the generation of the bicuculline-induced paroxysmal oscillation (Fig. 3B,D).

\section{PGN-like interlaminar cells form disynaptic loops with thalamocortical neurons}

One functionally important property of PGN neurons is that they form disynaptic reciprocal connections with thalamocortical cells in the A and C laminae of the ferret LGNd (von Krosigk et al., 1993; Bal et al., 1995a,b; Bal and McCormick, 1996). Here we examined whether PGN-like interlaminar interneurons may also form similar disynaptic connections with thalamocortical cells in the neighboring laminae of the LGNd.

In support of this hypothesis, we often observed the arrival of rhythmic barrages of EPSPs in interlaminar interneurons at a rate of $\sim 1-4 \mathrm{~Hz}(1.54 \pm 0.18 \mathrm{~Hz})$ in between the generation of spindle waves (Fig. 4). Close examination of these PSP barrages revealed that they consisted of 3-5 EPSPs with an interburst frequency of $125-280 \mathrm{~Hz}$, in similarity with the frequency range with which action potential are generated by thalamocortical cells during the generation of intrinsic bursts. This rhythmic pattern of EPSP barrages is similar to that which occurs spontaneously in a subpopulation of thalamocortical cells through intrinsic membrane mechanisms and which is known as the "delta" oscillation (McCormick and Pape, 1990a; Soltesz et al., 1991).

Further support for the excitation of interlaminar interneurons by thalamocortical cells was obtained with the activation of the later through the local application of glutamate in the A laminae (Fig. 5). Local application of glutamate $(\sim 2-10 \mathrm{pl}$ in a drop $\sim 8-25 \mu \mathrm{m}$ in diameter) within the $\mathrm{A}$ or A1 laminae resulted in the generation of barrages of EPSPs or IPSPs in interlaminar interneurons (Fig. 5A). The EPSPs arrived from lamina $\mathrm{A} 1$ at latencies of 30-40 msec, which suggests a direct monosynaptic connection (see Materials and Methods). Interestingly, the application of glutamate to lamina A1 excited these PGN-like interneurons in the interlaminar zone between A and A1 more often than did applications of glutamate to lamina A. IPSPs could also be activated from laminae $\mathrm{A}$ or $\mathrm{A} 1$, although these exhibited longer latencies (60-100 msec), suggesting that they are attributable to the activation of perigeniculate cells or PGN-like interlaminar interneurons by the excitation of thalamocortical cells 
A
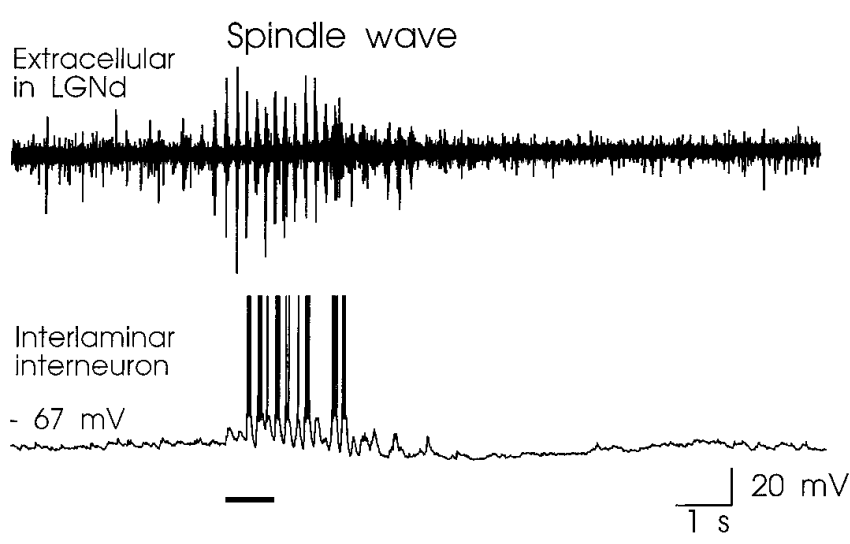

B

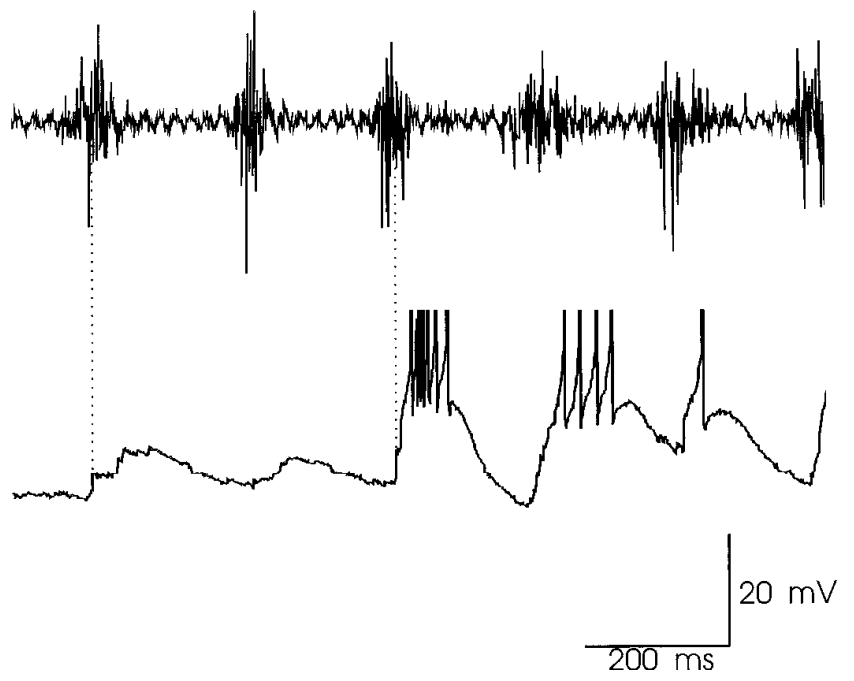

Bicuculline-induced slow oscillation
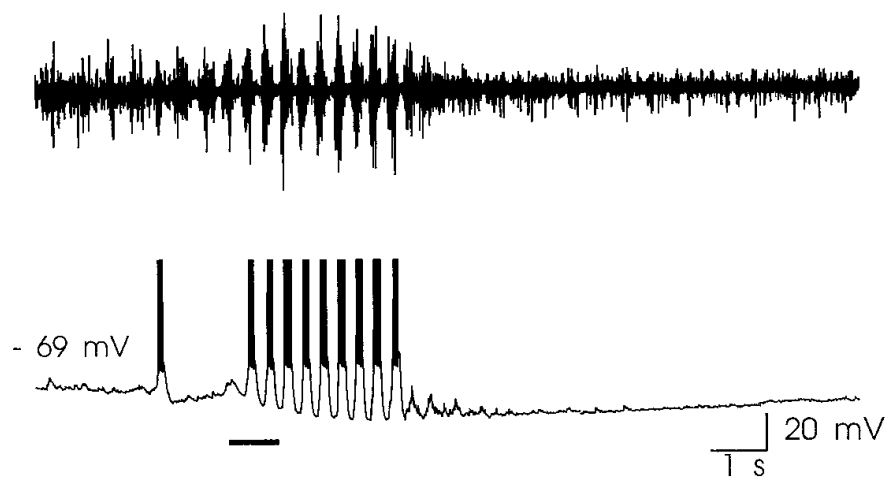

D

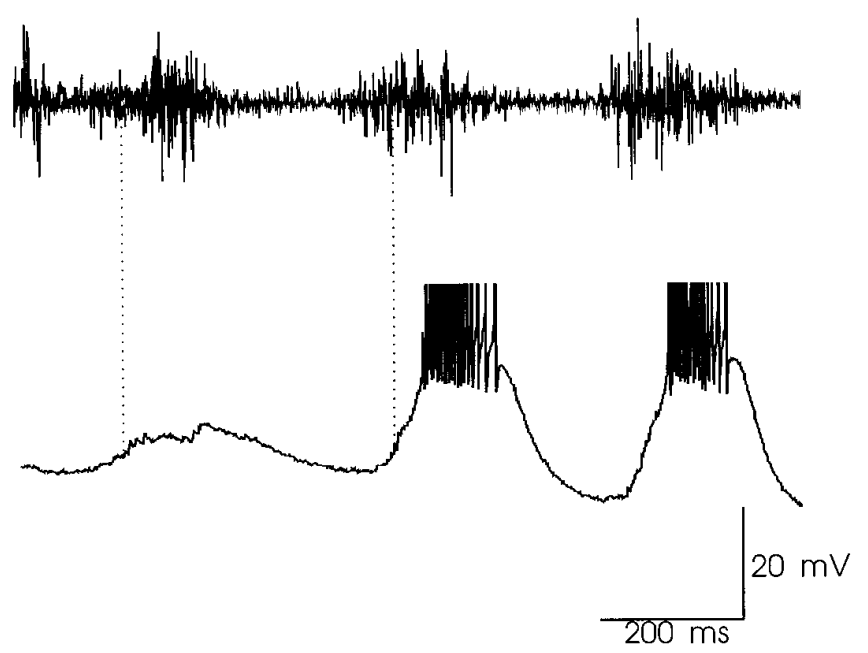

Figure 3. PGN-like interlaminar interneurons participate in the generation of synchronized network oscillations. $A$, Simultaneous intracellular recording from a PGN-like interlaminar neuron and an extracellular multiple-unit recording from lamina A during the generation of a spindle wave. $B$, Expansion of the indicated part of the recording in $A$ illustrates the arrival of barrages of EPSPs in the interlaminar neuron and the generation of low-threshold Ca ${ }^{2+}$ spike-mediated bursts of action potentials. $C$, Bath application of bicuculline-methiodide $(20 \mu \mathrm{M})$ transforms the oscillation into a synchronized slow oscillation characterized by strong burst firing in both the extracellular recording and the interlaminar neuron. $D$, Expansion of the indicated portion of the recording in $C$.

with glutamate (Fig. $5 A$, lamina $A$ ). In addition to the initial barrage of synaptic potentials, local application of glutamate in the A laminae or PGN typically also activated spindle waves. These glutamate-initiated spindle waves resulted in the arrival of cyclical barrages of EPSPs in PGN-like interlaminar interneurons after the initial barrage of EPSPs or IPSPs (see Fig. $5 B$ ).

Repeated application of glutamate in various regions of the $\mathrm{A}$ and A1 laminae during the intracellular recording from a PGNlike interlaminar interneuron revealed that these cells received presumed direct excitatory input from only a subportion of these laminae (Fig. 5). Indeed, it was often found that moving the glutamate-applying electrode by as little as $50 \mu \mathrm{m}$, either through the thickness of the slice or in the dorsal-ventral or anteriorposterior axis, could result in the abolition of the glutamateactivated EPSPs. This result suggests that the glutamate application remained localized to small regions of the laminae and that only localized regions project to the interlaminar interneurons.
In addition to receiving excitatory inputs from the A laminae, the PGN-like interlaminar interneurons were inhibited by application of glutamate in the PGN (Fig. 5B). Again, the region of the PGN that was effective in inhibiting interlaminar interneurons was relatively circumscribed, and repeated applications of glutamate at multiple locations were performed so as to identify these regions. In general, the regions of the A laminae and the PGN that provided synaptic inputs to the interlaminar interneurons were found to lie on the anterior-posterior axis, along the lines of retinotopic organization.

Intracellular injection of a depolarizing or hyperpolarizing current pulse into $\mathrm{PGN}$-like interlaminar neurons, so as to generate a low-threshold $\mathrm{Ca}^{2+}$-spike-mediated burst of action potentials, often resulted in the appearance of a barrage of EPSPs (Figs. 5C, $6,7)$. These return barrages of EPSPs were composed of a composite of small EPSPs similar to those that occur during the generation of a spindle wave (Fig. 6). The average latency for the 


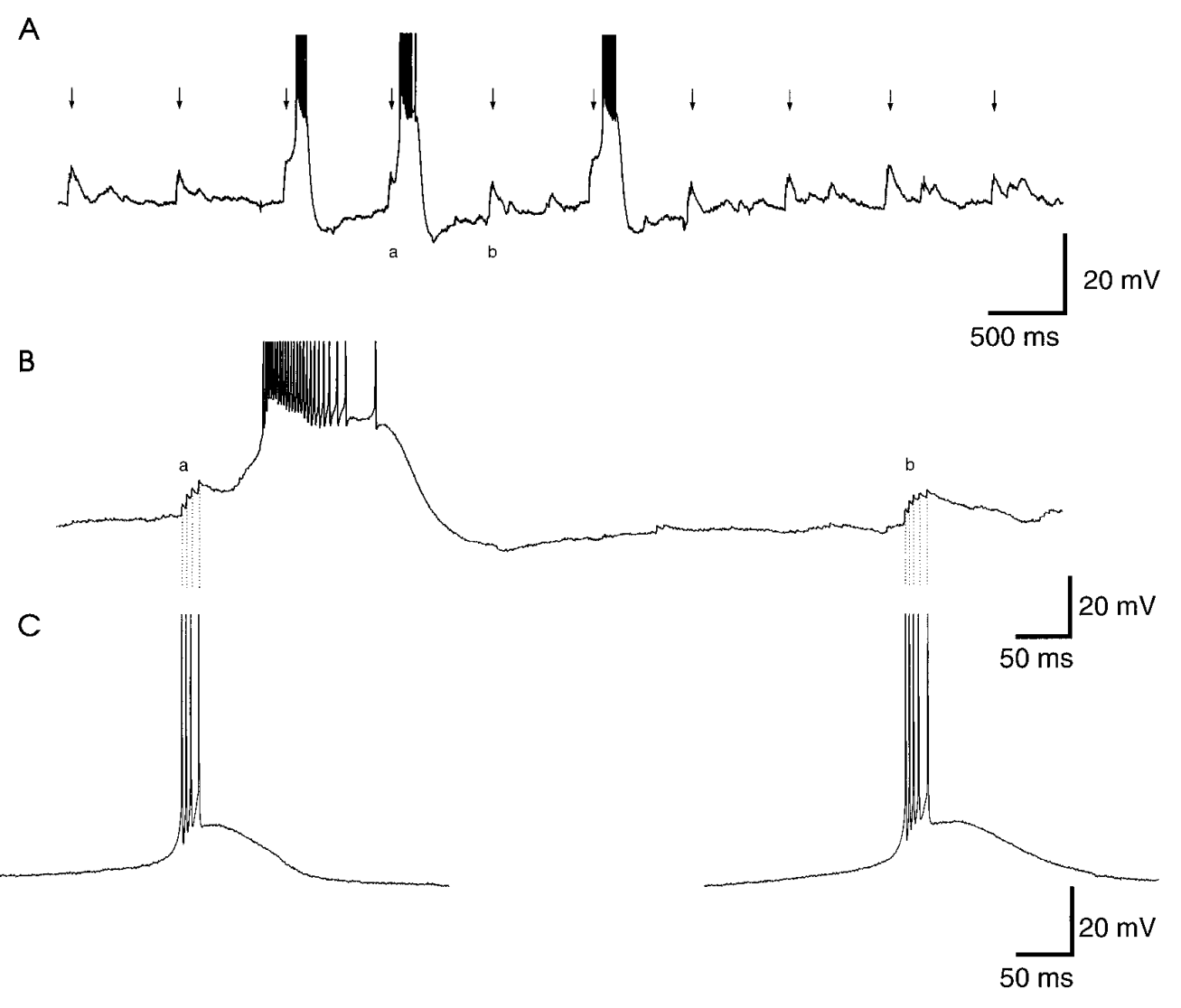

Figure 4. PGN-like interlaminar interneurons receive rhythmic barrages of EPSPs at $0.5-4 \mathrm{~Hz}$. $A$, Intracellular recording from a PGN-like interlaminar interneuron illustrating the regular occurrence of rhythmic barrages of EPSPs arriving at $\sim 1.5 \mathrm{~Hz}$ (indicated by arrows). $B$, Expansion of the indicated ( $a$, $b$ ) EPSP barrages illustrates that they are composed of 3-5 individual EPSPs that occurred at $125-280 \mathrm{~Hz}$ and overlapped temporally. These bursts of EPSPs presumably result from rhythmic bursts of action potentials in a single thalamocortical cell. $C$, Comparison of the action potential discharge of a bursting thalamocortical cell (chosen at random) with the EPSP barrage in the PGN-like interlaminar neuron. generation of these return barrages of EPSPs was $140 \pm 4 \mathrm{msec}$, which is similar to the interval between barrages of EPSPs during the generation of spindle waves (202 \pm 38 msec; Fig. 6). These data indicate that interlaminar interneurons form disynaptic loops with thalamocortical neurons in the $\mathrm{A}$ and $\mathrm{C}$ laminae.

We have reported recently that the ability of PGN neurons to induce rebound burst firing in thalamocortical cells, and a subsequent return barrage of EPSPs, is depressed after the generation of a spindle wave (Bal and McCormick, 1995, 1996). Similarly, the amplitude of return barrages of EPSPs in PGN-like interlaminar interneurons was also markedly depressed after the generation of a spindle wave, and this slowly recovered as the time since the last spindle wave lengthened (Fig. 7).

The ability of PGN-like interlaminar interneurons to activate return barrages of EPSPs after a burst of action potentials indicates that these cells inhibit thalamocortical neurons at least in part through the activation of $\mathrm{GABA}_{\mathrm{A}}$ receptors. We tested this hypothesis through the application of glutamate to the interlaminar zones while recording from thalamocortical cells in the neighboring A laminae (Fig. 8). Local application of glutamate to the interlaminar zone resulted in the generation of barrages of IPSPs in thalamocortical cells (Fig. $8 A$ ). Close examination of these barrages of IPSPs revealed on occasion that they consisted in part of discrete events occurring at frequencies of 50-70 $\mathrm{Hz}$ (Fig. 8A, enlargement).

Local application of bicuculline methiodide $(400 \mu \mathrm{m}$ in micropipette) to the interlaminar zones resulted in an enhancement of the IPSPs evoked by glutamate application (Fig. 8B). These IPSPs were mediated in large part through the activation of $\mathrm{GABA}_{\mathrm{A}}$ receptors, because local application of bicuculline to the region of the recorded thalamocortical cell resulted in a substantial decrease in their amplitude (Fig. $8 B$ ). Increasing the dose of glutamate application in the interlaminar zones resulted in an increasing amplitude of the evoked IPSPs, including those evoked in normal bathing medium (Fig. $8 C$ ) and those observed after the bath application of bicuculline (Fig. $8 C$ ).

These results suggest that the duration of burst discharges in PGN-like interlaminar neurons is enhanced by the local application of bicuculline. To test this hypothesis, we activated localized regions of either lamina A or lamina A1 with local glutamate application and examined the effects of local application of bicuculline to the intralaminar zones on the response of the PGN-like interlaminar neuron (Fig. 8D). Local application of bicuculline resulted in a substantial enhancement of the burst discharges in the interlaminar neuron evoked by the glutamate evoked EPSP barrages (compare Fig. 8, D1 and D3).

\section{Responses of interlaminar interneurons to neuromodulators}

We have demonstrated previously that application of 5-HT or the glutamate metabotropic receptor agonist trans-(1S,3R)-1-amino-1,2cyclopentanedicarboxylic acid $(1 S, 3 R$-ACPD) to perigeniculate neurons results in pronounced excitation (McCormick and Wang, 1991; Lee et al., 1994), whereas application of these neurotransmitters to intralaminar interneurons in the cat LGNd results in either no response or weak excitation (Pape and McCormick, 1995). In addition, application of ACh to perigeniculate neurons in the ferret LGNd results in rapid excitation mediated by nicotinic receptors followed by inhibition mediated by muscarinic receptors (Lee and McCormick, 1995), whereas application of this neurotransmitter to intralaminar interneurons typically results in the inhibitory response only (McCormick and Pape, 1988; Pape and McCormick, 1995). Here we tested the responses of PGN-like interlaminar interneurons to these neurotransmitters with the hypothesis that they would respond in a manner similar to that of PGN cells. 
A

\section{PGN}

monosynaptic inhibition

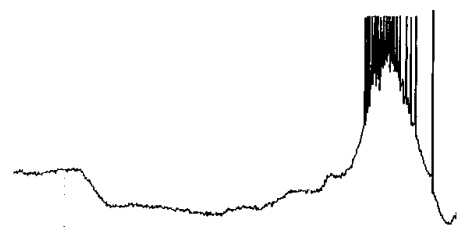

Al lamina

monosynaptic excitation

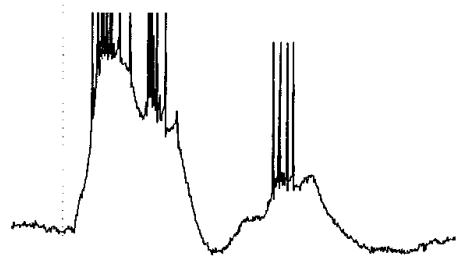

A lamina

inhibition-excitation

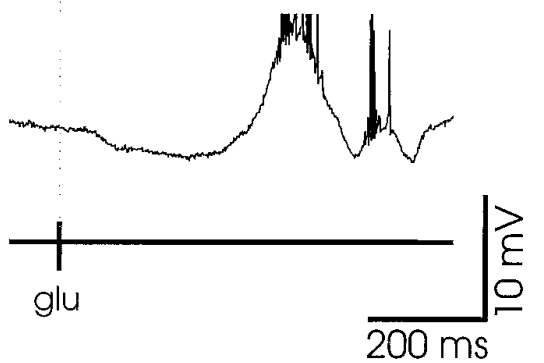

B

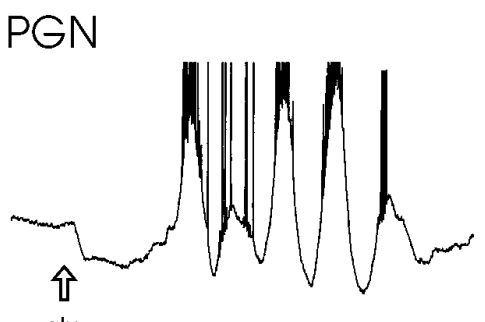

glu

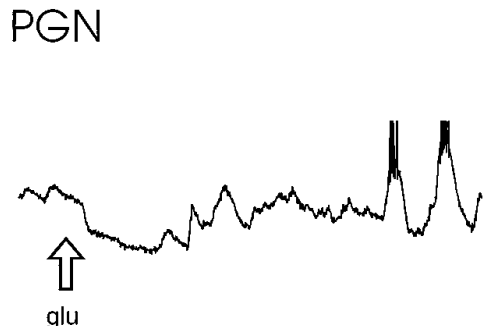

PGN

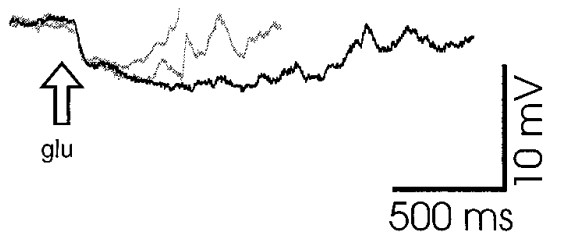

C

Feedback EPSPs

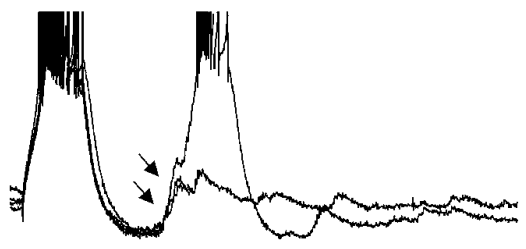

$100 \mathrm{~ms} \stackrel{\text { है }}{\circ}$
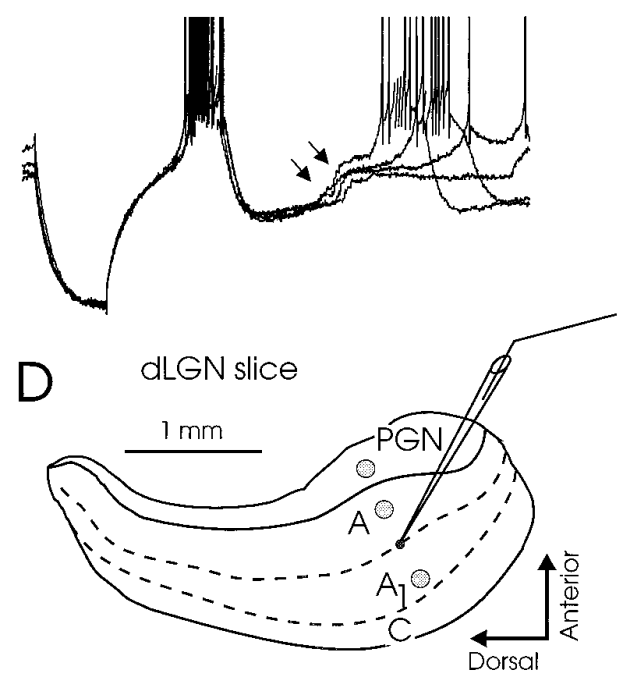

Figure 5. Interlaminar interneurons are excited by thalamocortical cells and inhibited by PGN neurons. $A$, Activation of laminae A or A1, or the PGN with the local application of glutamate ( $g l u ; 0.5 \mathrm{~mm}$ in micropipette) during an intracellular recording from a PGN-like interlaminar neuron. Activation of the PGN resulted in barrages of IPSPs followed by the generation of a spindle wave, which appeared as barrages of EPSPs and the generation of burst discharges (full spindle not shown). Pressure application of glutamate to lamina A1 resulted in the rapid activation of EPSPs in the interlaminar neuron. In contrast, pressure application of glutamate to lamina A resulted in the activation of IPSPs at a latency of $80-100$ msec, followed by the generation of a spindle wave. This long-latency inhibition probably results from the excitation of PGN or PGN-like interneurons by thalamocortical cells activated by glutamate. Each trace is the average of five consecutive glutamate applications with a $10-15$ sec interval. $B$, Increasing the duration of the glutamate application in the PGN increases the amplitude and duration of the inhibition of the PGN-like interlaminar neuron. $C$, Activation of a burst of action potentials through the intracellular injection of a depolarizing or hyperpolarizing current pulse in this interlaminar neuron results in the generation of return or feedback EPSPs, indicating that the cell is disynaptically connected with thalamocortical cells. $D$, Illustration of the intracellular recording site and locations of glutamate applications corresponding to the recordings in $A$.

Application of 5-HT (500 $\mu \mathrm{M}$ in micropipette) resulted in a prolonged depolarization of interlaminar interneurons $(n=3$; Fig. $9 A)$. This prolonged depolarization was associated with a switch from the burst firing mode to the single-spike mode of action potential generation (Fig. 9A), as well as a decreased responsiveness to the barrages of EPSPs occurring during the generation of a spindle wave (Fig. 9A). In contrast, application of 5-HT to intralaminar interneurons resulted either in no detectable response $(n=2)$ or in a prolonged hyperpolarization that was associated with an increase in membrane conductance $(n=2$; Fig. $9 C)$. As in the cat and guinea pig LGNd (McCormick and Pape, 1990b), application of 5-HT to ferret thalamocortical neurons resulted in only a 1-3 $\mathrm{mV}$ depolarization that was associated with an increase in membrane conductance (data not shown).

Similar to 5-HT, application of $1 S, 3 R$-ACPD $(0.5 \mathrm{~mm}$ in micropipette) to PGN-like interlaminar interneurons also resulted in a pronounced depolarization (Fig. 9D) as well as the activation of tonic activity. The application of ACh to PGN-like interlaminar interneurons was associated with a rapid depolarization and the generation of action potentials followed by a more prolonged hyperpolarization (Fig. 9E). In contrast, application of ACh to local interneurons resulted in the hyperpolarizing response only (data not shown). Finally, local application of the neuropeptide cholecystokinin-8-sulfate (CCK-8-S) (Fig. 9F) to PGN-like interlaminar interneurons resulted in a prolonged depolarization of the membrane potential, as found for cells in the thalamic reticular or perigeniculate nuclei (Cox et al., 1995) (K. Lee and D. McCormick, unpublished observations).

\section{PGN-like interlaminar interneurons densely innervate the relay laminae}

Four PGN-like interlaminar neurons were intracellularly filled with biocytin. The cell bodies of these neurons were situated within the interlaminar zones either between laminae A and A1 


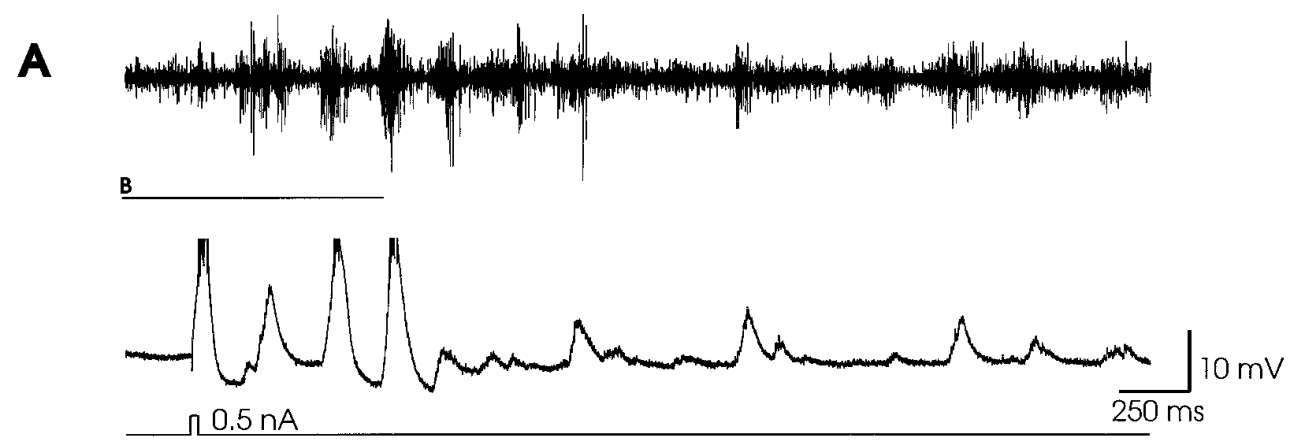

B
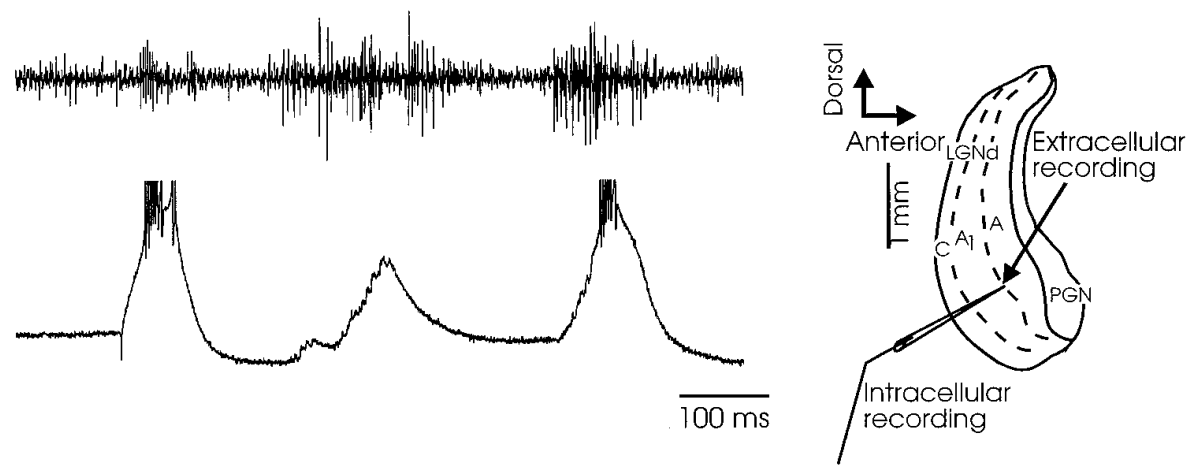

C

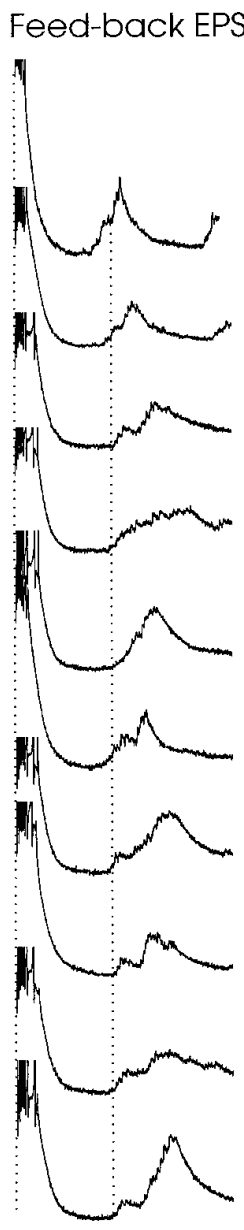

Spindle EPSPS

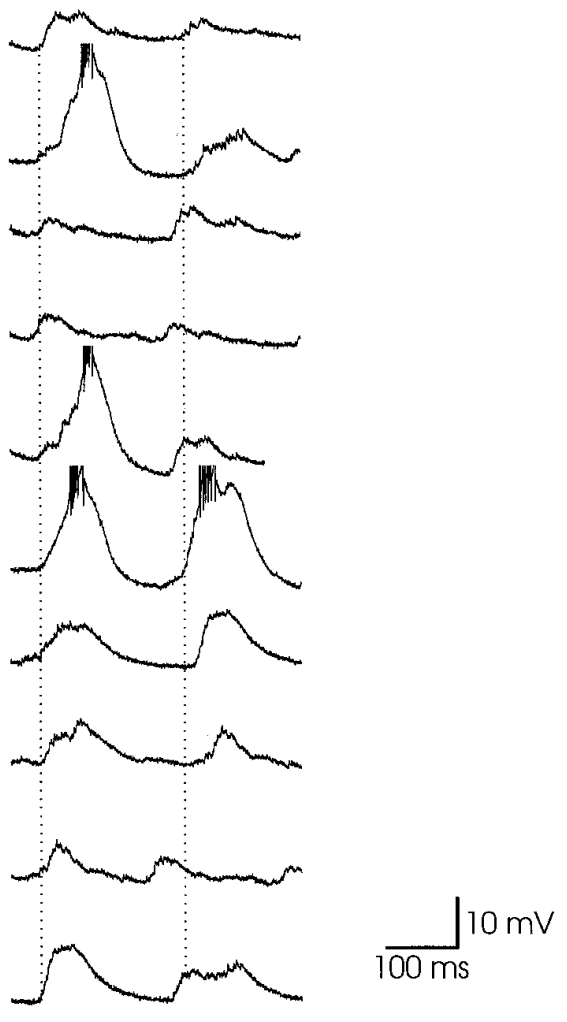

Figure 6. Characteristics of return EPSPs in PGN-like interlaminar interneurons. $A$, Intracellular injection of a depolarizing current pulse in a PGNlike interlaminar interneuron located between laminae $\mathrm{A}$ and $\mathrm{A} 1$ results in the generation of return barrages of EPSPs as well as a short spindle wave. $B$, Expansion of the indicated portion in $A$. $C$, Several examples of return EPSPs generated by burst firing in this neuron are illustrated. The average latency for the onset of these return EPSPs is 140 msec from the first action potential in the burst. Also illustrated are barrages of EPSPs that occur during the generation of a spindle wave. Here the average latency between barrages is $202 \mathrm{msec}$. 
Figure 7. The amplitude of feedback EPSPs in PGN-like interlaminar interneurons is decreased during the spindle wave refractory period. $A, B$, Intracellular injection of a depolarizing current pulse while the cell is hyperpolarized to $-76 \mathrm{mV}$ results in the generation of feedback EPSPs that could also activate another burst of action potentials. After the generation of a spindle wave, the amplitude of the feedback EPSP barrage was markedly reduced. $C$, Average peak amplitude of the feedback EPSP barrages before and after the generation of a spindle wave. Both SD and SEM are indicated on each bar. Also indicated is the number of observations for each time period in this cell.

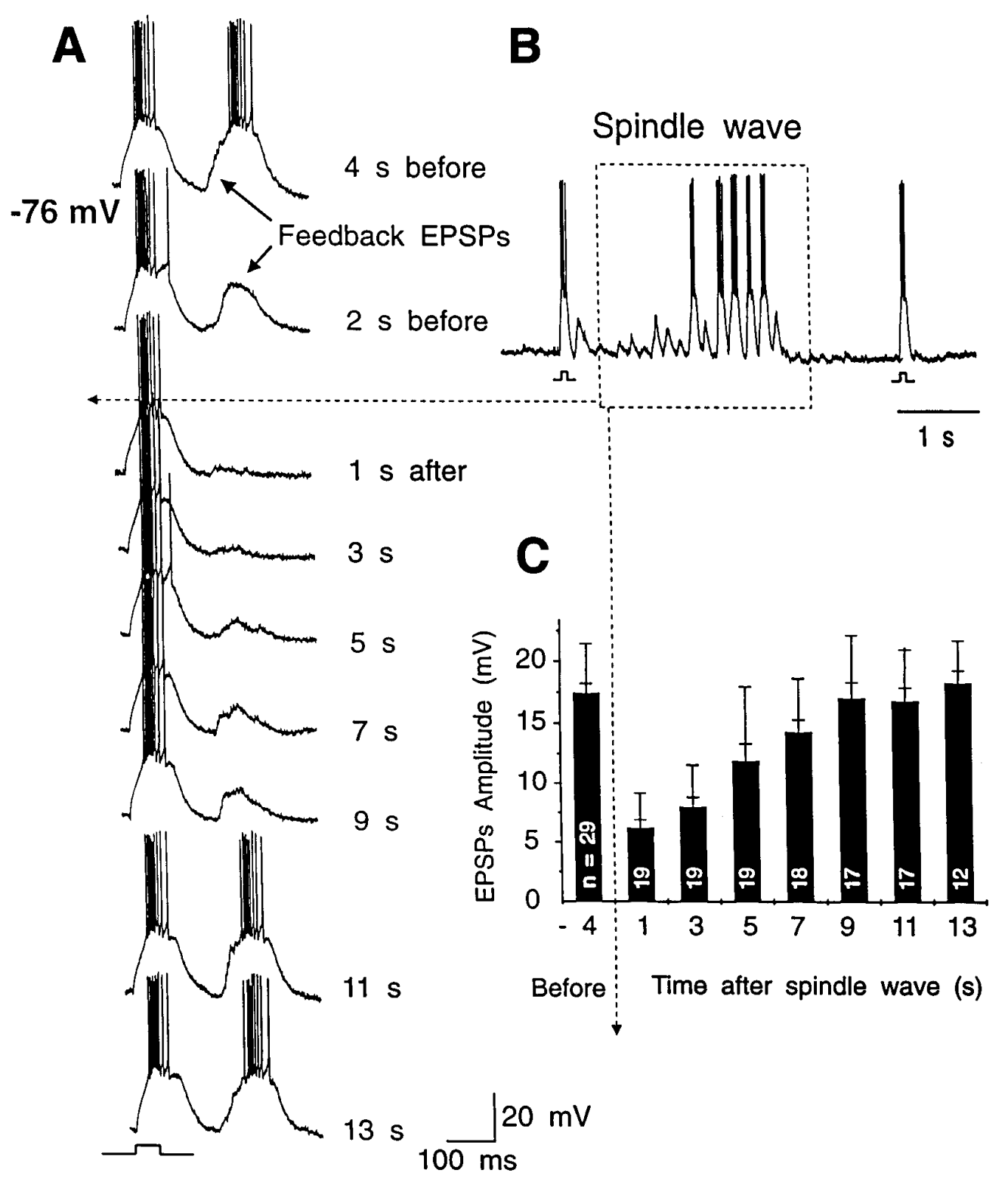

passed through lamina A, and then to bifurcate within the PGN (Fig. 10). In the other three cells, presumed axonal collaterals densely innervated the local neuropil within the field of the dendritic arbor within the interlaminar zone as well as extending into the adjacent lamina. In two of the three cells there appeared to be a preference for the innervation of the more posterior laminae, i.e., lamina $\mathrm{A} 1$ for one cell and lamina $\mathrm{C}$ for the other. The other cell, located between laminae A and A1, gave rise to a dense innervation of lamina A and only a sparse innervation of lamina A1. Interestingly, this cell also received strong barrages of EPSPs when lamina A was activated locally with glutamate application.

\section{Thalamocortical cells give rise to axon collaterals in the interlaminar zones}

Close examination of axons emanating from thalamocortical cells revealed on occasion axon collaterals within the interlaminar zones between $\mathrm{A}$ and $\mathrm{A} 1(n=6)$ or between $\mathrm{A} 1$ and $\mathrm{C}(n=1)$, with the main branch of the axon extending toward the PGN and optic radiation (Fig. 11). These axonal branches appeared as fine 


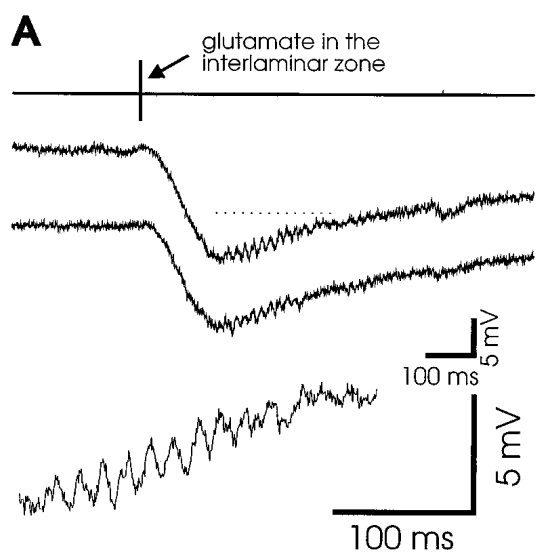

C<smiles>[OH+][OH+]</smiles>

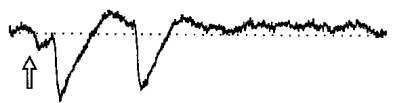

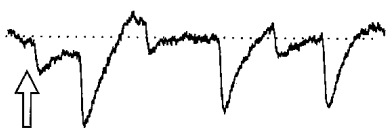

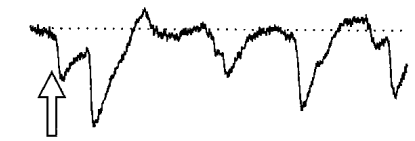
glutamate in the
interlaminar zone

D

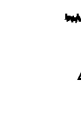

B

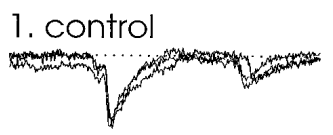

2. bicuculline in the I.Z.<smiles>C#CCCOc1ccc(C)cc1</smiles>

3. bicuculline at the relay cell

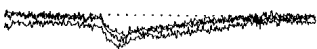<smiles>[C]1[C]=C1</smiles>
\

glutamate in the

interlaminar zone

$5 \mathrm{mV}$

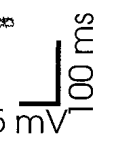

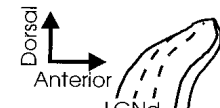

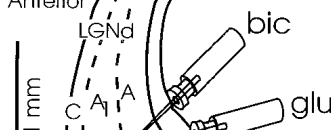

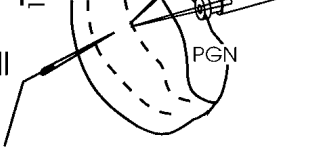

\section{Control}

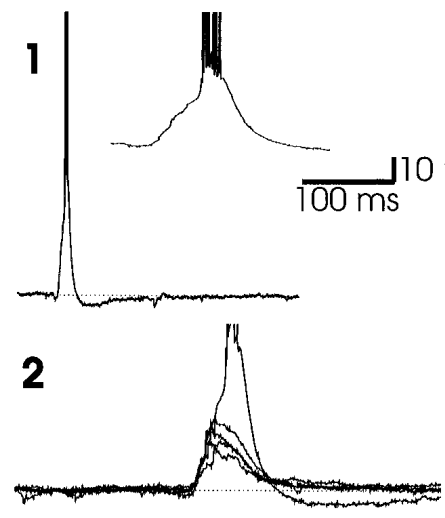

Bicuculline in bath
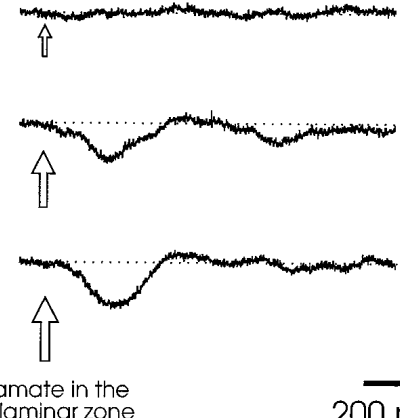

interlaminar zone

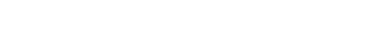



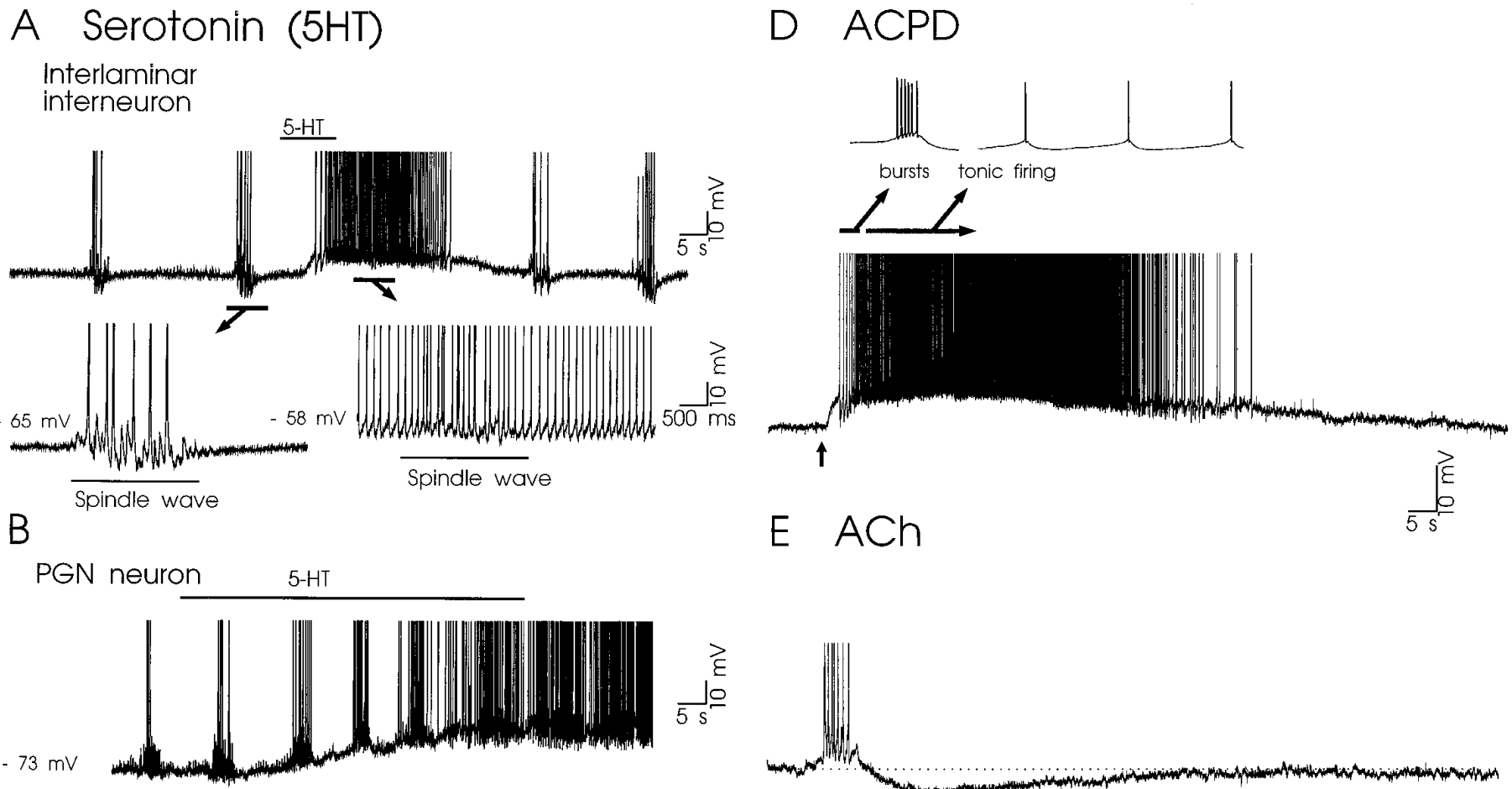

C

Intralaminar

interneuron
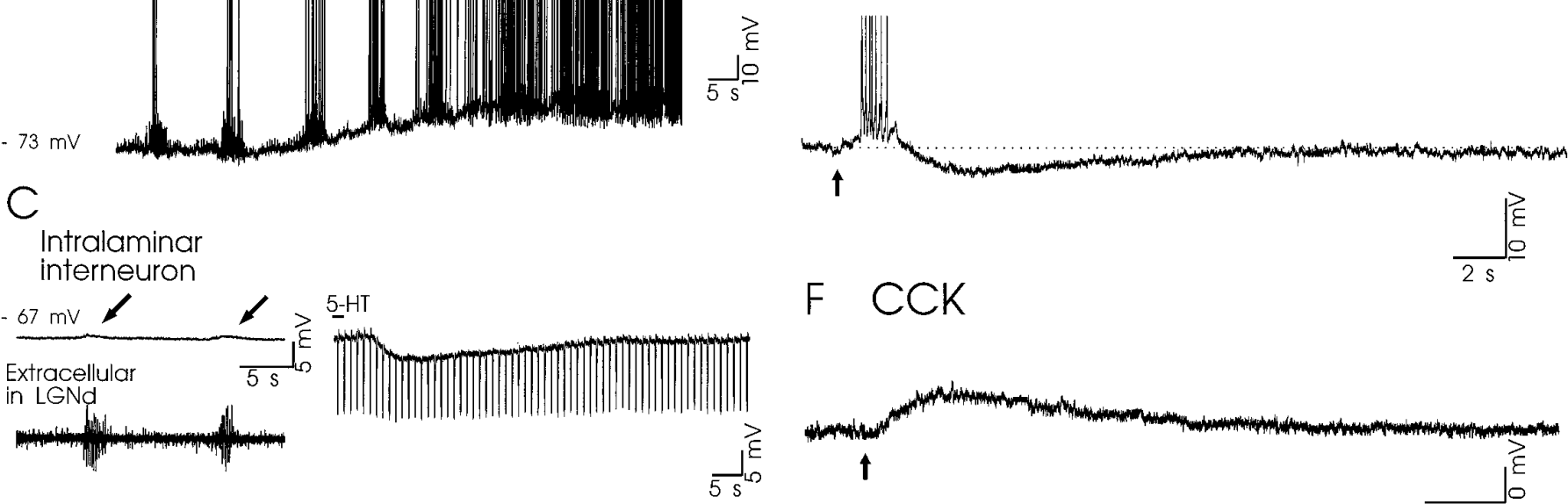

F CCK

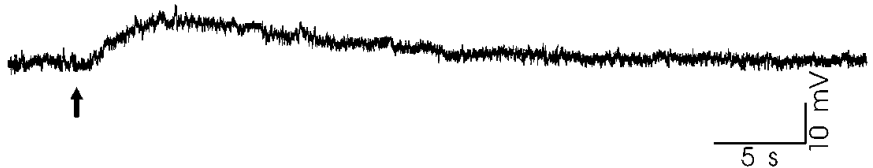

Figure 9. PGN-like interlaminar neurons are pharmacologically similar to PGN neurons, but not local interneurons. $A$, Intracellular recording from a PGN-like interlaminar interneuron during the generation of spindle waves. Local application of serotonin ( $5 H T$; $0.5 \mathrm{~mm}$ in micropipette) results in membrane depolarization, the occurrence of single-spike activity, and the inhibition of burst firing. $B$, Application of 5-HT to a PGN neuron exhibits the same response. $C$, Intracellular recording from a classical intralaminar interneuron during the generation of a spindle wave reveals that this cell exhibits only small $(\sim 1 \mathrm{mV})$ depolarizations during these events (arrows). Application of 5-HT to this cell results in membrane hyperpolarization. $D$, Local application of $1 S, 3 R$-ACPD (500 $\mu \mathrm{M}$ in micropipette) results in a prolonged depolarization and switch from the burst to single-spike mode of action potential generation. $E$, Local application of acetylcholine $(A C h)$ to a PGN-like interlaminar interneuron results in a rapid excitation followed by a more prolonged hyperpolarization. $F$, Local application of the peptide CCK8S $(C C K)$ to a PGN-like interlaminar interneuron results in a slow depolarization of the membrane potential.

processes extending into the interlaminar zones from the parent axon as it traveled through the laminae toward the optic radiation. Each process typically took a circuitous route in the local neuropil of the interlaminar zone and could give rise to additional axon collaterals (Fig. 11). Each axon collateral exhibited repeated swellings at intervals of $\sim 2-8 \mu \mathrm{m}$, presumably representing presynaptic terminals. The full extent of innervation of the interlaminar zone in the dorsal-ventral plane varied from 50 to $100 \mu \mathrm{m}$, and the average number of swellings was $28 \pm 14(n=7)$. No thalamocortical neurons were observed to give rise to axon collaterals in an interlaminar zone that was posterior to the location of their cell body (i.e., not on the trajectory between their cell body and the optic radiation). The same axons that provided collaterals within the interlaminar zones also gave rise to collaterals within the perigeniculate nucleus (Fig. 11). Collaterals within the perigeniculate nucleus typically were slightly more extensive than those in the interlaminar zones, extending from 100 to $300 \mu \mathrm{m}$ in the dorsal-ventral plane (for example, see Fig. 11).

Examination of the axonal arbors of perigeniculate neurons in the ferret LGNd sometimes revealed dense innervations of the interlaminar zones $(n=6$; Fig. 12). The axonal arbors of some PGN neurons were found to selectively innervate restricted regions of both the $\mathrm{A}$ and $\mathrm{C}$ laminae as well as either the interlaminar zones between A and A1 or between A1 and C (Fig. 12).

\section{Parvalbumin- and calbindin-containing cells in the interlaminar region}

Previous examination of parvalbumin and calbindin cells in the cat LGNd have demonstrated that PGN cells are positive for parvalbumin, but not for calbindin (Demeulemeester et al., 1991). Similarly, we found the ferret PGN contained a high density of parvalbuminpositive neurons (Fig. 13C), but a low density of calbindin-positive 


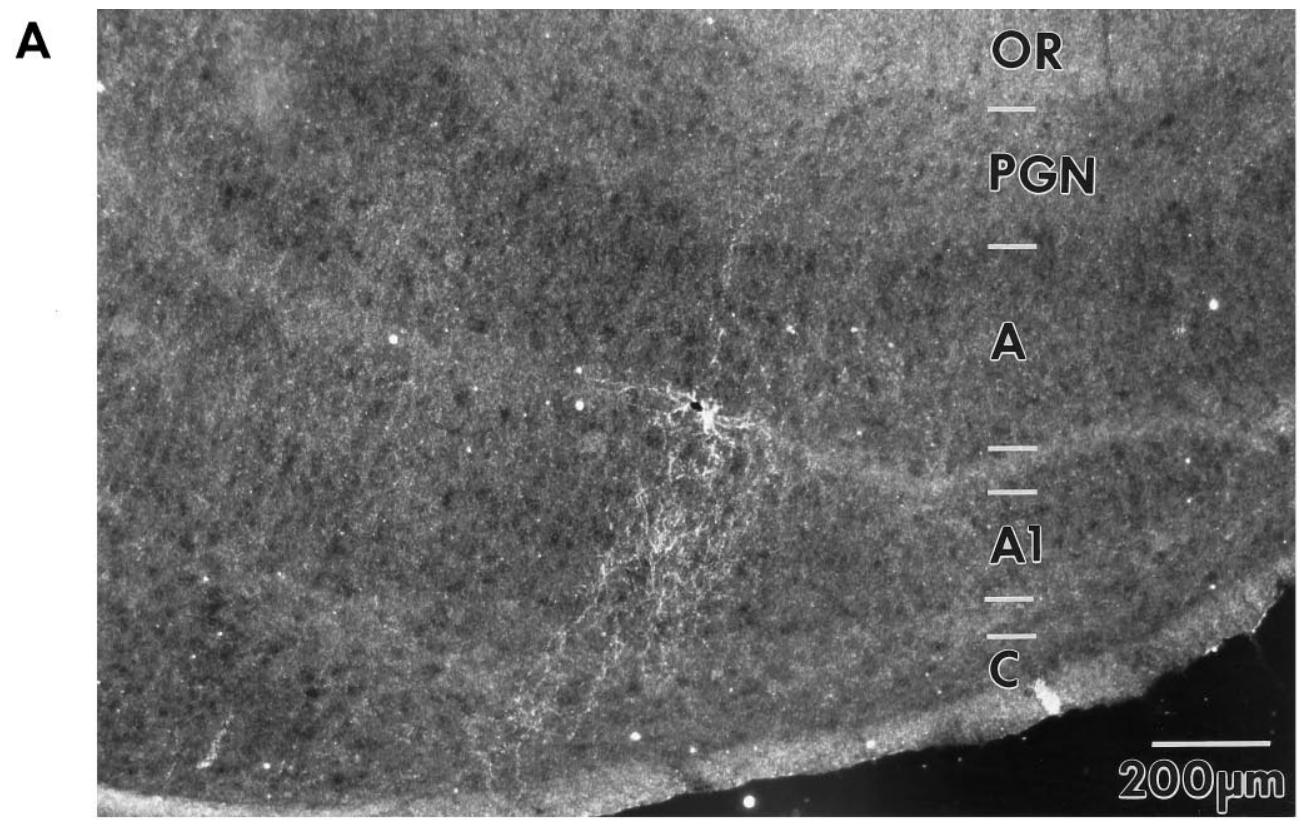

B

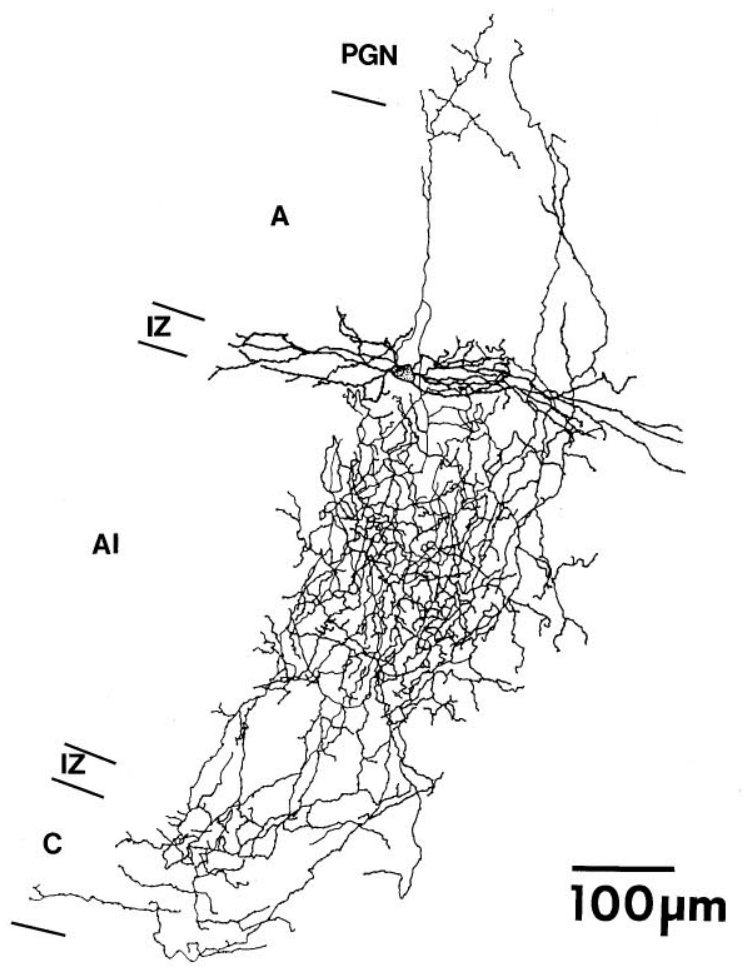

Figure 10. Morphological properties of a PGN-like interlaminar interneuron. $A$, Dark-field illumination of a PGN-like interlaminar interneuron. $B$, Camera lucida reconstruction of the cell in $A$. The cell body and dendrites were located in the A-A1 interlaminar zone (IZ). The axon densely innervated lamina A1 and also innervated lamina $C$. One branch of the axon passed through lamina $\mathrm{A}$ and into the PGN. Recordings from this neuron are illustrated in Figures 2, 4, 8D, and $9 D$.

cells (Fig. 13B). Parvalbumin neurons were also present in the interlaminar zone between laminae A and A1 (Fig. 13C, 14) at the rate of $\sim 3-10$ per $20 \mu \mathrm{m}$ section. Close examination of these cells revealed that they often possessed initial dendritic segments that were oriented in parallel with the long axis of the interlaminar zones (Fig. 14 $A, B$ ). In addition to parvalbumin-positive neurons, calbindinpositive neurons were also found within or adjacent to the interlaminar zones (3-7 per section; see Fig. 13B). Preliminary results with double-immunofluorescent labeling of calbindin and parvalbumin suggest that the parvalbumin and calbindin-positive cells in the interlaminar zones are two distinct populations of cells (M. von Krosigk, unpublished observations).

Examination of Nissl-stained sagittal sections of the ferret
LGNd revealed not only clearly defined interlaminar zones between laminae $\mathrm{A}$ and $\mathrm{A} 1$, but also a relatively cell-free zone between lamina A and the PGN (Fig. 13A). Examination of this zone between lamina A and the PGN revealed that it was similar to the interlaminar zone between $\mathrm{A}$ and $\mathrm{A} 1$ in that it contained parvalbumin-positive cells as well as, on rare occasions, calbindinpositive cells. Intracellular recordings from this zone reveal a mixture of cells with the electrophysiological properties of thalamocortical or perigeniculate cells.

\section{DISCUSSION}

Based on the types of synaptic contacts found with electron microscopic examination of GABAergic interlaminar interneu- 
A

PGN

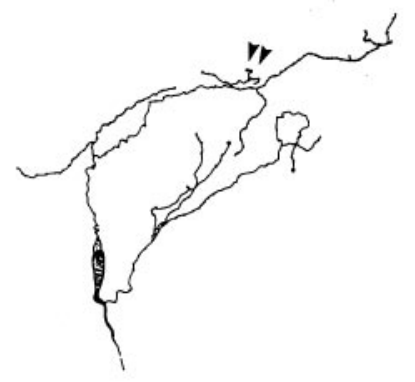

A

Figure 11. Thalamocortical cells can give rise to axon collaterals in the interlaminar zones and in the perigeniculate nucleus. $A$, Camera lucida reconstruction of a thalamocortical cell in lamina A1. $B$, Dark-field illumination of this thalamocortical neuron. $C$, Photograph of axon collaterals in the PGN. D, Photograph of axon collaterals in the interlaminar zone between laminae A and A1. This thalamocortical cell gave rise to axon collaterals in both the interlaminar zone $(A, B, D)$ and the PGN $(A-C)$. The reconstruction in $A$ is of the section photographed in $B$.
B
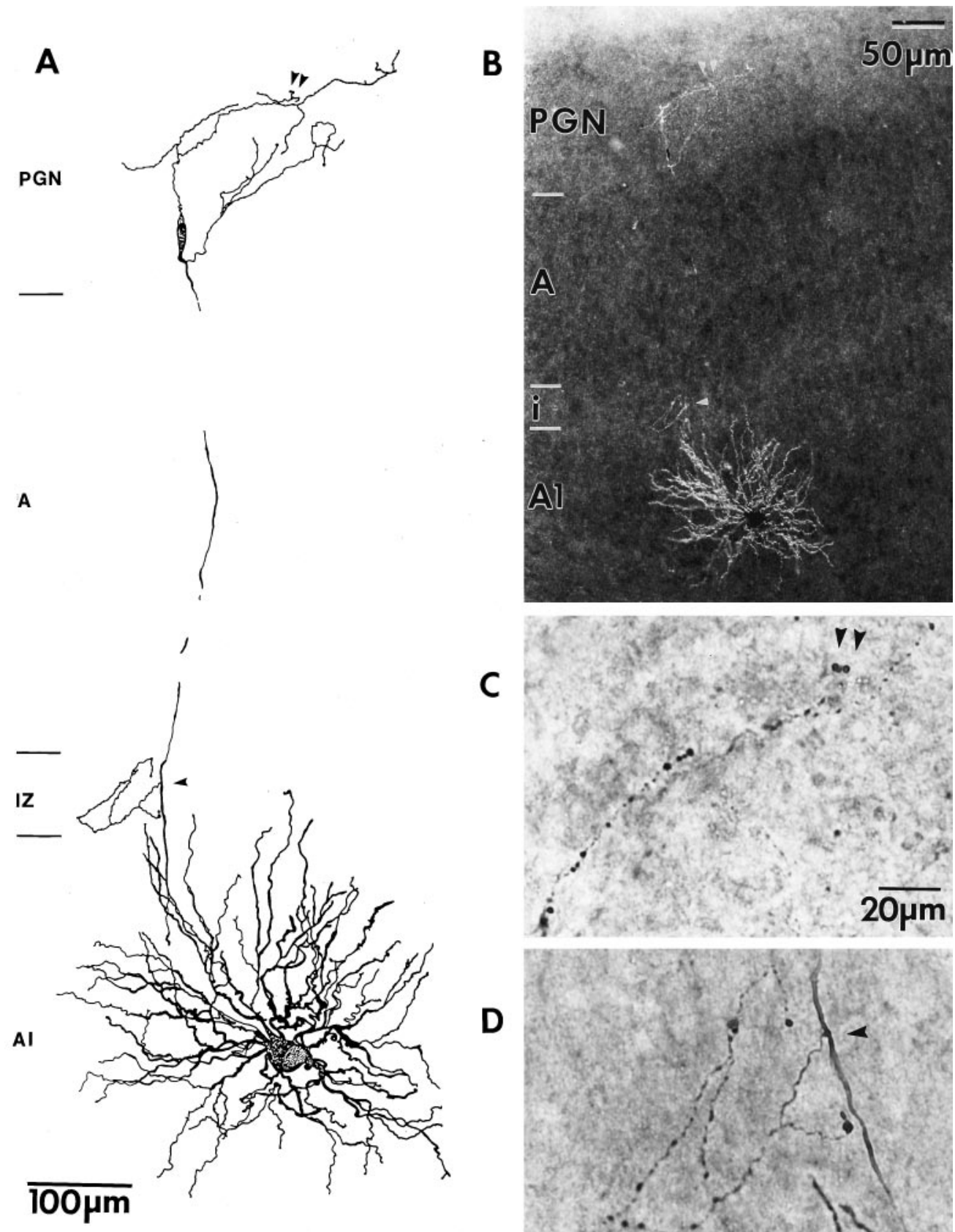

rons in the cat LGNd, as well as the orientation of primary dendrites and soma size, Montero (1989a) suggested that these neurons may function in a manner that is similar to the GABAergic cells of the perigeniculate nucleus and distinct from other GABAergic neurons within the LGNd. Our data strongly support this hypothesis. We have demonstrated here that PGN-like interlaminar interneurons have similar electrophysiological, anatomical, pharmacological, and functional properties to perigeniculate cells. Indeed, the similarities are so great that the only feature that we have found that allows us to distinguish between these two cell types is the location of their cell body and dendritic processes.

Electrophysiologically, PGN-like interlaminar interneurons and PGN neurons both exhibit two modes of action potential generation. At membrane potentials negative to approximately -60 $\mathrm{mV}$, these neurons are capable of generating rhythmic low- threshold $\mathrm{Ca}^{2+}$ spikes and bursts of action potentials. These rhythmic bursts of action potentials are interspaced with the generation of afterhyperpolarizations and can be followed by the generation of a prolonged tail of action potentials (for example, see Fig. 2). Tonic depolarization of the membrane potential with the intracellular injection of current results in a suppression of this rhythmic burst firing and the generation of single-spike firing only (Avanzini et al., 1989; Bal and McCormick, 1993).

Anatomically, PGN-like interlaminar interneurons exhibit dendritic arbors and axonal interconnections that are similar to those of PGN cells. The dendritic arbor of our small sample of PGN-like interlaminar interneurons was often oriented parallel to the interlaminar zones, similar to the orientation of the dendritic arbors of perigeniculate neurons (Szentágothai, 1972; Ide, 1982; Montero and Singer, 1984; Uhlrich et al., 1991). This orientation 

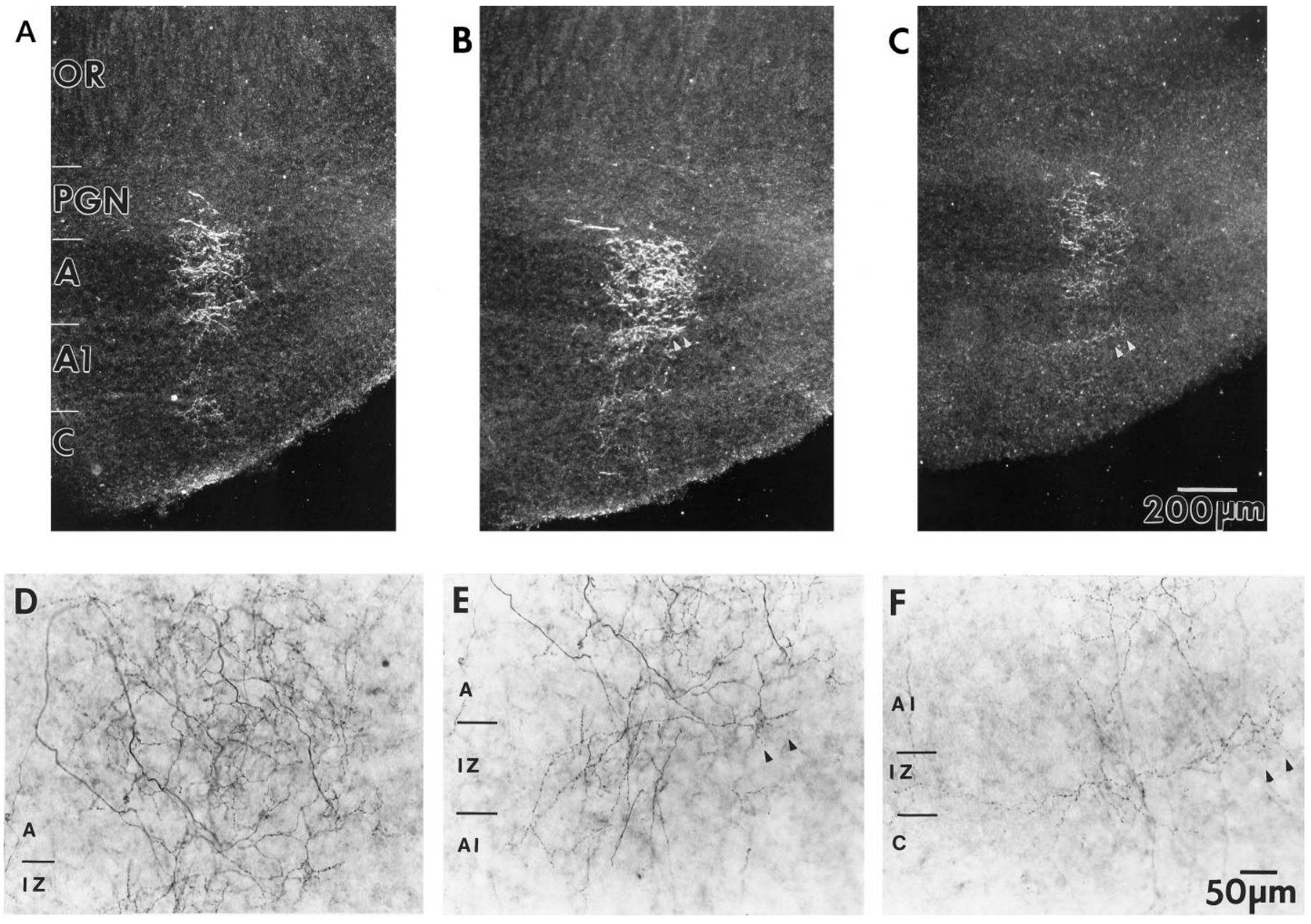

Figure 12. Perigeniculate neurons can innervate the interlaminar zones. $A-C$, Dark-field illumination of sequential $75 \mu \mathrm{m}$ sections through the axonal innervation of the A and C laminae and interlaminar zones by a PGN neuron. $D-F$, Higher-magnification photographs of the axon collaterals in the laminae and interlaminar zones (IZ). This PGN neuron densely innervates lamina A $(D)$ and the interlaminar zone between A and A1 $(E)$ as well as between $\mathrm{A} 1$ and $\mathrm{C}(F)$. Double arrowheads in $B$ and $C$ are for orientation in $E$ and $F$, respectively.

is perpendicular to the lines of projection and retinotopic organization of the LGNd (Sanderson, 1971). In contrast, intralaminar interneurons exhibit dendritic arbors that are often in line with the retinotopic organization of the $\mathrm{LGNd}$ and, therefore, are perpendicular to the orientation of the $\mathrm{A}$ and $\mathrm{C}$ laminae.

The axonal interconnections of both PGN-like interlaminar interneurons and PGN cells reveal that both form disynaptic loops with thalamocortical cells. PGN-like interlaminar interneurons densely innervated laminae adjacent to the interlaminar zone in which their cell body is located. Our examination of intracellularly filled thalamocortical cells reveals that some of these cells give rise to axon collaterals that form putative synaptic contacts in the interlaminar zone between $\mathrm{A}$ and $\mathrm{A} 1$ and between $\mathrm{A} 1$ and $\mathrm{C}$, in agreement with previous examination of the intrageniculate axonal projections of thalamocortical cells (Friedlander et al., 1981; Montero, 1989a). We assume that these axon collaterals are a significant source of the axonal input to interlaminar interneurons from thalamocortical cells. However, not all collaterals within the LGNd are in the interlaminar zones (Friedlander et al., 1981; Humphrey and Weller, 1987). It is possible that these intralaminar collaterals also synapse on PGN neurons or PGN-like interlaminar neurons, because a subpopulation of both PGN-like interlaminar interneurons and perigeniculate cells sends dendrites into the
A and C laminae. Intracellular recordings from thalamocortical cells have revealed, on rare occasions, small EPSPs that appear to arise from other thalamocortical cells (Soltesz and Crunelli, 1992). Similarly, intracellular recordings from intralaminar interneurons also reveal small phasic depolarizations during the generation of spindle waves in vitro, suggesting that these cells may also receive a very weak innervation from thalamocortical cells. Together, these results suggest that PGN-like interlaminar interneurons or PGN neurons are by far the preferred target of thalamocortical axon collaterals, although they are not the exclusive target. Local axon collaterals are relatively rare in other thalamic nuclei (see Jones, 1985), and this may be explained by the lack of a laminar structure, and therefore a lack of interlaminar zones, in these nuclei.

Interestingly, we found that interlaminar interneurons are inhibited by activation of perigeniculate neurons, in a manner similar to the inhibition of perigeniculate cells by other perigeniculate neurons (Bal et al., 1995b; Sanchez-Vives et al., 1995). In contrast, intrageniculate interneurons are not inhibited by activity in perigeniculate neurons (Bal et al., 1995a).

Pharmacologically, PGN-like interlaminar interneurons and PGN neurons were quite similar, yet distinct from intralaminar interneurons. Both PGN and PGN-like interlaminar interneurons 

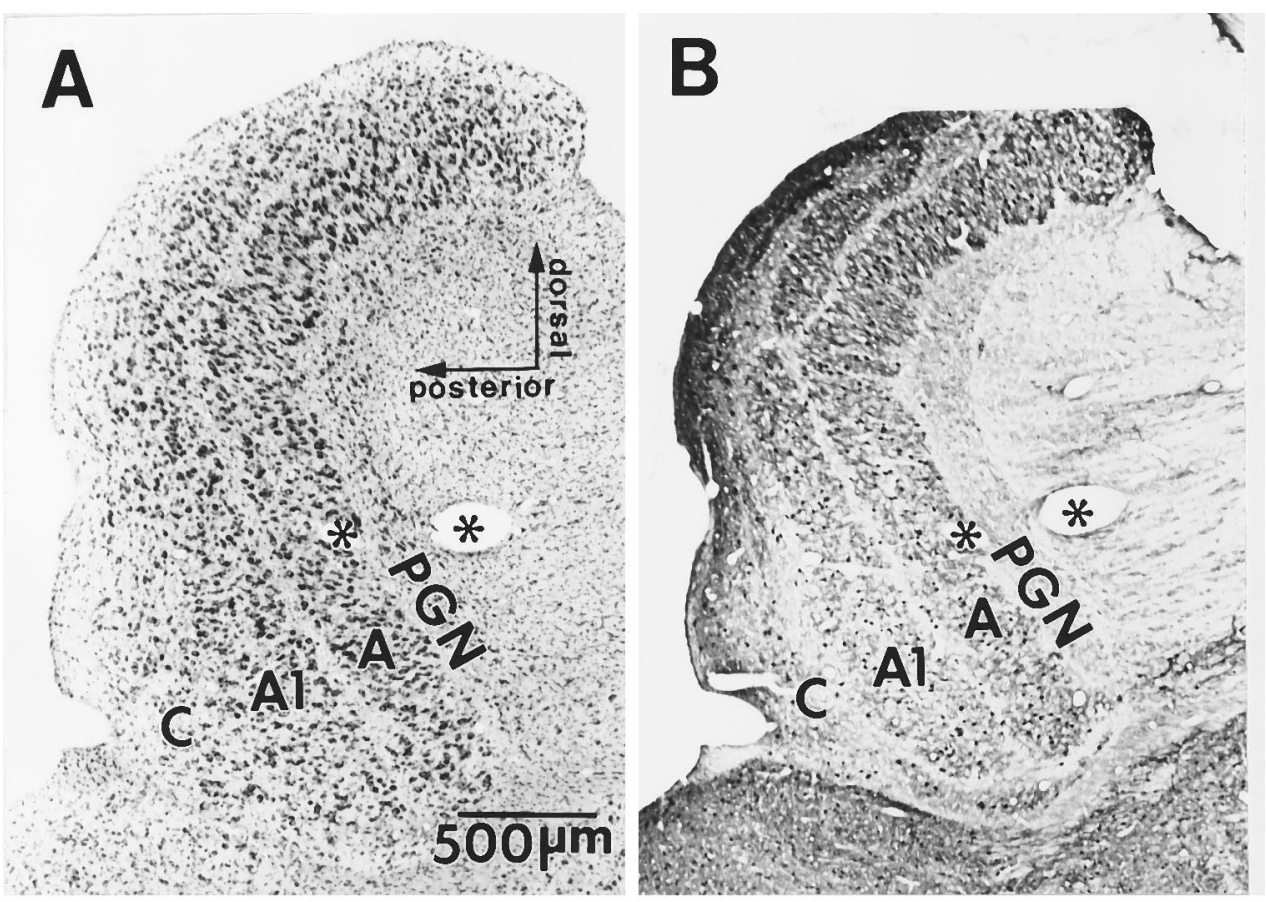

Figure 13. Parvalbumin- and calbindinimmunoreactive cells in the ferret geniculate. $A$, Nissl stain of a sagittal slice of the ferret geniculate. The interlaminar zone between A and A1 is clearly seen as a relatively cell-sparse region. Note that a similar region occurs between lamina A and the PGN. B, Calbindinimmunoreactive cells in an adjacent section. Calbindin-positive cells are found throughout the A and C laminae but not in the PGN. Occasional calbindin-positive cells are found in the interlaminar zones. $C$, Parvalbuminpositive cells are found throughout the PGN and in the interlaminar zone between laminae $\mathrm{A}$ and $\mathrm{A} 1$. The indicated area is illustrated in Figure 14. Sections $A-C$ are adjacent $20 \mu \mathrm{m}$ sections. The asterisks indicate the same blood vessel. $D$, GABA-immunoreactive cells in the ferret LGNd. GABA-immunoreactive cells are found in the PGN and throughout the intralaminar and interlaminar regions of the LGNd.
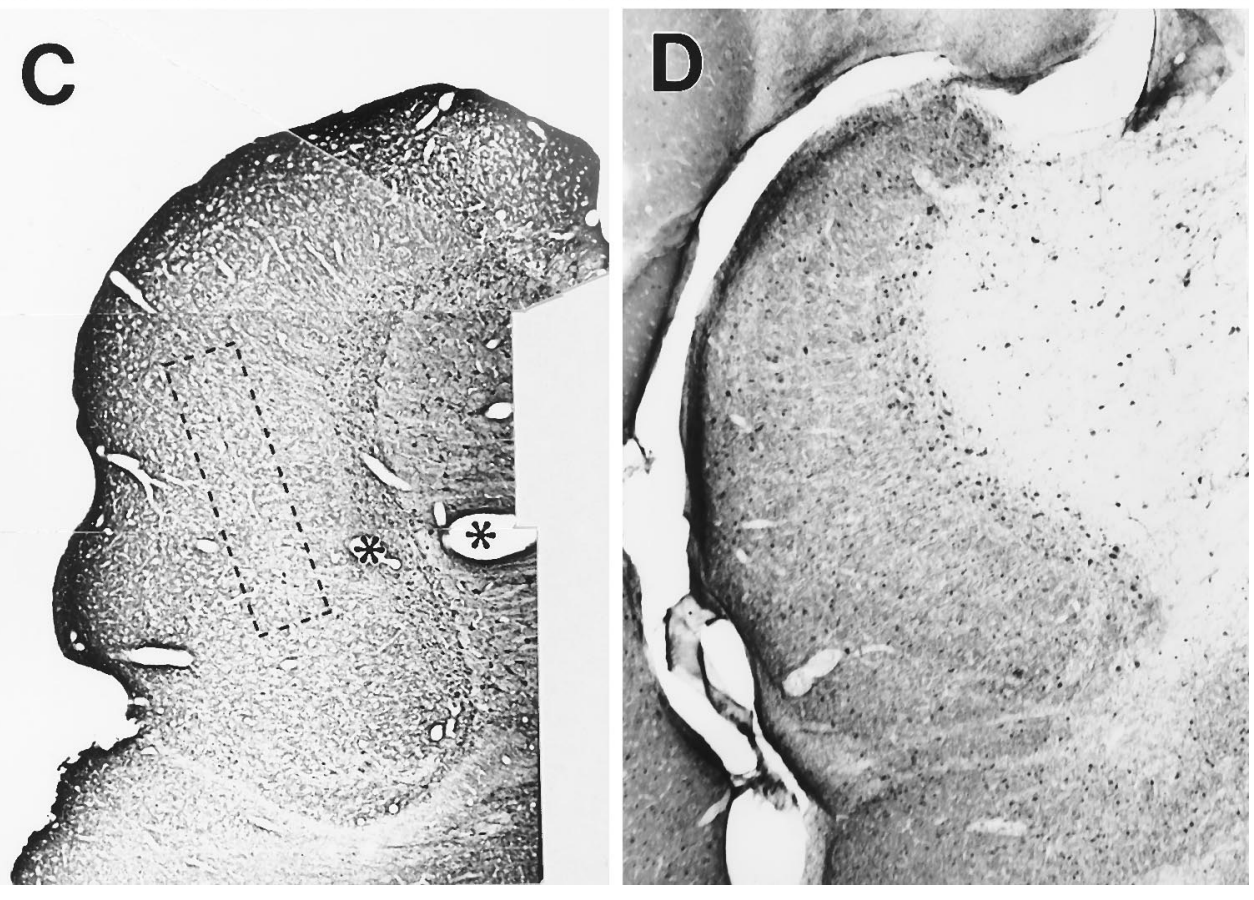

were strongly depolarized by 5 -HT, by the glutamate metabotropic receptor agonist $1 S, 3 R-\mathrm{ACPD}$, and by CCK8S, and they also exhibited a rapid excitatory response, followed by a more prolonged hyperpolarizing response, to ACh (McCormick and Wang, 1991; Lee et al., 1994; Cox et al., 1995). Intralaminar interneurons, in contrast, are not strongly excited by $1 S, 3 R$ ACPD, 5-HT, or ACh (Pape and McCormick, 1995).

Functionally, we have demonstrated that both PGN and PGNlike intralaminar interneurons from disynaptic loops with thalamocortical cells, such that the activation of a burst of action potentials in a PGN-like interlaminar or PGN interneuron can generate a rebound burst of action potentials in several thalamocortical cells, which then results in the generation of a return barrage of EPSPs (Bal et al., 1995b; Bal and McCormick, 1996).
The existence of this reciprocity between PGN-like interlaminar interneurons and thalamocortical cells indicates that these connections are formed in a relatively precise manner, although the full extent of the axonal projections of interlaminar interneurons remains to be determined. The axonal projections of single PGN cells are restricted to a relatively selective portion of the $\mathrm{A}$ laminae $(\sim 300-500 \mu \mathrm{m})$ in the cat and ferret LGNd (Uhlrich et al., 1991) (U. Kim, T. Bal, M. Sanchez-Vives, and D. McCormick, unpublished observations). Likewise, collateral projections from thalamocortical cells in the perigeniculate nucleus are typically limited to $\sim 100-300 \mu \mathrm{m}$ (our unpublished observations). Our preliminary observations reveal a similar level of precision in the anatomical interactions between PGN-like interlaminar interneurons and thalamocortical cells. 


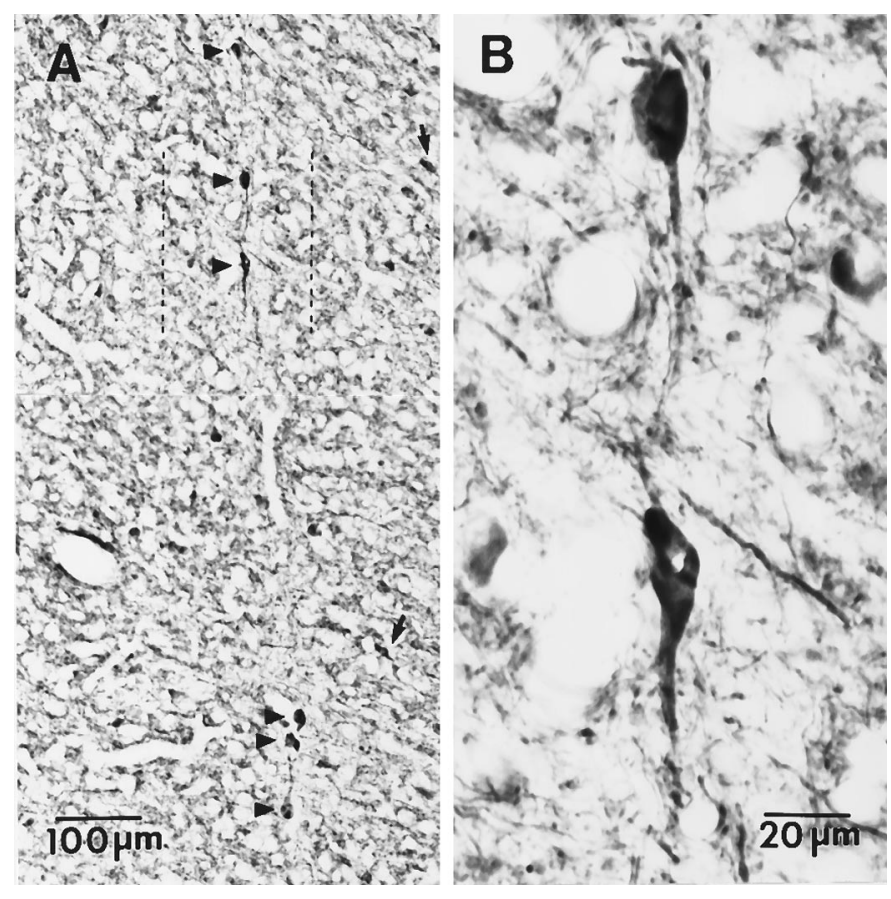

Figure 14. Photograph of parvalbumin-positive cells in the interlaminar zone between A and A1 (indicated by arrowheads). B. Close-up of two of the parvalbumin-positive cells. Note that the initial segments of the dendrites are parallel to the interlaminar zone.

The timing of the disynaptic loop between PGN-like interlaminar interneurons and thalamocortical cells indicates that these cells inhibit thalamocortical neurons through $\mathrm{GABA}_{\mathrm{A}}$ receptors (see Bal et al., 1995a,b). This hypothesis is consistent with the amplitude and time course of inhibition that occurs in thalamocortical cells after activation of the interlaminar zone with local application of glutamate. That interlaminar interneurons may also activate $\mathrm{GABA}_{\mathrm{B}}$ receptors is suggested by the finding that local application of glutamate in the interlaminar zones can activate a bicuculline-resistant slow IPSP (Fig. $8 C$ ). Activation of the PGN can activate both $\mathrm{GABA}_{\mathrm{A}}$ and $\mathrm{GABA}_{\mathrm{B}}$ receptors in thalamocortical cells, depending on the strength of activation (Huguenard and Prince, 1994; Bal et al., 1995a,b; Sanchez-Vives et al., 1995). Another possibility, however, is that extracellular application of glutamate in the interlaminar zones activated the processes of intralaminar interneurons or non-PGN-like interlaminar interneurons, and that it was these cells that gave rise to the fast and slow IPSPs in thalamocortical cells.

As with perigeniculate cells, the presence of disynaptic loops between PGN-like interlaminar cells and thalamocortical neurons allows for the interlaminar cells to actively participate in the generation of spindle waves and bicuculline-induced paroxysmal oscillations (Bal et al., 1995a,b). In the ferret LGNd, spindle waves are generated as an interaction between perigeniculate GABAergic neurons and thalamocortical cells in which burst firing in the perigeniculate cells inhibits thalamocortical cells through the activation of $\mathrm{GABA}_{\mathrm{A}}$ receptors. This inhibition results in the generation of rebound low-threshold $\mathrm{Ca}^{2+}$ spikes and bursts of action potentials, which once again excite the cells of the PGN. The pharmacological block of $\mathrm{GABA}_{\mathrm{A}}$ receptors results in the transformation of spindle waves into a paroxysmal oscillation (von Krosigk et al., 1993; Bal et al., 1995a,b), that resembles that which occurs during spike-and-wave seizures in animal models of absence epilepsy (Avoli et al., 1983). We have proposed previously that this transition results, at least in part, from the disinhibition of PGN neurons from one and another, thereby allowing for the generation of prolonged and high-frequency spike trains observed in these neurons (Bal et al., 1995a,b).

The generation of spindle waves and the bicuculline-induced slow oscillation are associated with a relative refractory period of 5-20 sec during which the threshold for activation of additional network oscillations is dramatically increased (Kim et al., 1995; Bal and McCormick, 1996). Recent investigations have demonstrated that this relative refractory period is generated in part through a persistent activation of the hyperpolarization-activated cation current $I_{\mathrm{h}}$ in thalamocortical cells. This persistent activation of $I_{\mathrm{h}}$ results in a decrease in the ability of burst firing in PGN neurons to generate rebound bursts of action potentials in thalamocortical cells (Bal and McCormick, 1996). Our present results suggest that there is a similar decrease in the ability of PGN-like interlaminar interneurons to generate rebound burst responses in thalamocortical neurons after the generation of spindle waves, because the amplitude of feedback EPSP barrages was markedly decreased by these events.

The examination of the distribution of neurons that contain parvalbumin, a low molecular weight calcium-binding protein, in the rat, guinea pig, cat, and primate LGNd have demonstrated marked species differences. However, the PGN in all species is positive for the presence of parvalbumin (Stichel et al., 1988; Demeulemeester et al., 1989; Jones and Hendry, 1989; Luth et al., 1993; De Biasi et al., 1994). Calbindin immunoreactivity in the rat LGNd reveals that this calcium-binding protein is restricted to putative interneurons (Luth et al., 1993). In the cat, calbindinimmunoreactive cells are found largely in the relay laminae and are relatively sparse in the PGN (Demeulemeester et al., 1991).

As in other species, we found that the cells of the ferret perigeniculate nucleus stain intensely for the presence of parvalbumin, and not for calbindin. However, we also found parvalbumin-positive neurons to be present in the interlaminar zones of the ferret LGNd and to be relatively sparse within the relay laminae. Calbindin-positive cells were relatively sparse in the ferret PGN but were abundantly present within the relay laminae. Calbindin-positive cells were also relatively sparse within the interlaminar zones, although some were clearly present. Although we have not yet directly examined this, we propose that the PGN-like interlaminar interneurons that we have characterized here may be represented by the parvalbumin-containing neurons, similar to those of the perigeniculate nucleus.

Developmentally, the ferret PGN and LGNd exhibit distinct origins with the perigeniculate forming from the ventral thalamus and the LGNd arising from the dorsal thalamus (see Mitrofanis, 1994). During the first two postnatal weeks, the ferret LGNd progressively obtains its laminated structure as the ipsilateral and contralateral retinogeniculate fibers segregate (Linden et al., 1981). The developmental origins of the PGN-like interlaminar interneurons is not known. They may represent displaced PGN cells that survive in the zones between the laminae of the LGNd or else they may selectively migrate to occupy these positions. Presumably the same developmental signals that guide the establishment of the proper connectivity of the PGN also are present in the PGN-like interlaminar interneurons. Although further investigations will be required, these results suggest that, at least in the case of the LGNd and PGN, thalamic cells of dorsal and ventral thalamic origin may be more intimately interrelated than previously appreciated. 
The anatomical or physiological properties of interlaminar zone GABAergic neurons have only been examined in the cat (Montero, 1989a) and ferret (present study). However, the similarity in structure and location of the perigeniculate and lateral geniculate nuclei in various carnivores suggests that the findings in cat and ferret may apply generally to these species (Sanderson, 1974; Jones, 1985). It is unclear whether or not similar neurons exist in primates. The interlaminar zones of the primate LGNd do contain occasional GABAergic neurons, although these are relatively rare (Montero and Zempel, 1986; Hendry, 1991). In addition, in the primate, these interlaminar zones also contain thalamocortical relay cells with distinct visual response properties and axonal projections (Hendry and Yoshioka, 1994). Development of a specific immunocytochemical marker for thalamic reticular cells would help to clarify this issue.

In conclusion, we suggest that there exist in the interlaminar zones in the carnivore LGNd neurons that are functionally equivalent to perigeniculate neurons in every regard. Indeed, we propose that these neurons are actually part of the perigeniculate nucleus. One possibility that requires further examination is that the PGN actually forms a continuous sheet of GABAergic neurons that gives rise to laminae or "fingers" that penetrate within the body of the LGNd such that the layers of PGN and LGNd are intercalated.

\section{REFERENCES}

Aghajanian GK, Rasmussen K (1989) Intracellular studies in the facial nucleus illustrating a simple new method for obtaining viable motoneurons in adult rat brain slices. Synapse 3:331-338.

Avanzini G, de Curtis M, Panzica F, Spreafico R (1989) Intrinsic properties of nucleus reticularis thalami neurones of the rat studied in vitro. J Physiol (Lond) 416:111-122.

Avoli M, Gloor P, Kostopoulos G, Gotman J (1983) An analysis of penicillin-induced generalized spike and wave discharge using simultaneous recordings of cortical and thalamic single neurons. J Neurophysiol 50:819-837.

Bal T, McCormick DA (1993) Ionic mechanisms of rhythmic burst firing and tonic activity in the nucleus reticularis thalami: a mammalian pacemaker. J Physiol (Lond) 468:669-691.

Bal T, McCormick DA (1995) A mechanism for the waning of thalamic spindle and "absence-seizure like" oscillations in vitro. Soc Neurosci Abstr 21:11.

Bal T, McCormick DA (1996) What stops synchronized thalamocortical oscillations? Neuron, in press.

Bal T, von Krosigk M, McCormick DA (1995a) Synaptic and membrane mechanisms underlying synchronized oscillations in the ferret LGNd in vitro. J Physiol (Lond) 483:641-663.

Bal T, von Krosigk M, McCormick DA (1995b) Role of the ferret perigeniculate nucleus in the generation of synchronized oscillations in vitro. J Physiol (Lond) 483:665-685.

Contreras D, Curró Dossi R, Steriade M (1993) Electrophysiological properties of cat reticular thalamic neurones in vivo. J Physiol (Lond) 470:273-294.

Cox CL, Huguenard JR, Prince DA (1995) Cholecystokinin depolarizes rat thalamic reticular neurons by suppressing a $\mathrm{K}^{+}$conductance. J Neurophysiol 74:990-1000.

De Biasi S, Arcelli P, Spreafico R (1994) Parvalbumin immunoreactivity in the thalamus of guinea pig: light and electron microscopic correlation with gamma-aminobutyric acid immunoreactivity. J Comp Neurol 348:556-569.

Demeulemeester H, Vandesande F, Orbain GA, Heizmann CW, Pochet R (1989) Calbindin D-28K and parvalbumin immunoreactivity is confined to two separate neuronal subpopulations in the cat visual cortex whereas partial coexistence is shown in the dorsal lateral geniculate nucleus. Neurosci Lett 99:6-11.

Demeulemeester H, Arckens L, Vandesande F, Orban GA, Heizmann CW, Pochet R (1991) Calcium binding proteins as molecular markers for cat geniculate neurons. Exp Brain Res 83:513-520.
Domich L, Oakson G, Steriade M (1986) Thalamic burst patterns in the naturally sleeping cat: a comparison between cortically projecting and reticularis neurones. J Physiol (Lond) 379:429-449.

Dubin MW, Cleland BG (1977) The organization of visual inputs to interneurons of the lateral geniculate nucleus of the cat. J Neurophysiol 40:410-427.

Ferster D, LeVay S (1978) The axonal arborization of lateral geniculate neurons in the striate cortex of the cat. J Comp Neurol 182:923-944.

Friedlander MJ, Lin CS, Stanford LR, Sherman SM (1981) Morphology of functionally identified neurones in the lateral geniculate nucleus of the cat. J Neurophysiol 46:80-129.

Guillery RW (1970) The laminar distribution of retinal fibers in the dorsal lateral geniculate nucleus of the cat: a new interpretation. J Comp Neurol 138:339-368.

Hamos JE, Van Horn SC, Rackowski D, Uhlrich DJ, Sherman SM (1985) Synaptic connectivity of a local circuit neurone in lateral geniculate nucleus of the cat. Nature 317:618-621.

Hendry SHC (1991) Delayed reduction in GABA and GAD immunoreactivity of neurons in the adult monkey dorsal lateral geniculate nucleus following monocular deprivation or enucleation. Exp. Brain Res $86: 47-59$.

Hendry SHC, Yoshioka T (1994) A neurochemically distinct third channel in Macaque dorsal lateral geniculate nucleus. Science 264:575-577.

Horikawa K, Armstrong WE (1988) A versatile means of intracellular labeling: injection of biocytin and its detection with avidin conjugates. J Neurosci Methods 25:1-11.

Hu B, Steriade M, Deschênes M (1989) The effects of brainstem peribrachial stimulation on perigeniculate neurons: the block of spindle waves. Neuroscience 31:1-12.

Huguenard JR, Prince DA (1994) Intrathalamic rhythmicity studied in vitro nominal $\mathrm{T}$ current modulation causes robust anti-oscillatory effects. J Neurosci 14:5845-5502.

Humphrey AL, Weller R (1987) Structural correlates of functionally distinct X-cells in the lateral geniculate nucleus of the cat. J Comp Neurol 268:448-468.

Ide LS (1982) The fine structure of the perigeniculate nucleus in the cat. J Comp Neurol 210:317-334.

Jahnsen H, Llinás R (1984a) Electrophysiological properties of guineapig thalamic neurons: an in vitro study. J Physiol (Lond) 349:205-226.

Jahnsen H, Llinás R (1984b) Ionic basis for the electroresponsiveness and oscillatory properties of guinea-pig thalamic neurons in vitro. J Physiol (Lond) 349:227-247.

Jones EG (1985) The thalamus. New York: Plenum.

Jones EG, Hendry SHC (1989) Differential calcium binding protein immunoreactivity distinguishes classes of relay neurons in monkey thalamic nuclei. Eur J Neurosci 1:222-246.

Jones HE, Sillito AM (1994) The length-response properties of cells in the feline perigeniculate nucleus. Eur J Neurosci 6:1199-1204.

Kim U, Bal T, McCormick DA (1995) Spindle waves are propagating synchronized oscillations in the ferret LGNd in vitro. J Neurophysiol 74:1301-1323.

Kozak W, Rodieck RW, Bishop PO (1965) Responses of single units in lateral geniculate nucleus of cat to moving visual patterns. J Neurophysiol 28:19-47.

Lee K, McCormick DA (1995) Acetylcholine excites GABAergic neurons of the ferret perigeniculate nucleus through nicotinic receptors. J Neurophysiol 73:2123-2128.

Lee K, Bal T, McCormick DA (1994) Waking up the sleeping slice: neuromodulation of spindle waves in vitro. Soc Neurosci Abstr 20:133.

Linden DC, Guillery RW, Cucchiaro J (1981) The dorsal lateral geniculate nucleus of the normal ferret and its postnatal development. J Comp Neurol 203:189-211.

Luth HJ, Winkelmann E, Celio MR (1993) Light- and electron microscopic localization of parvalbumin, Calbindin D-28K and calretinin in the dorsal lateral geniculate nucleus of the rat. J Hirnforsch 34:47-56.

McCormick DA, Pape HC (1988) Acetylcholine inhibits identified interneurons in the cat lateral geniculate nucleus. Nature 334:246-248.

McCormick DA, Pape HC (1990a) Properties of a hyperpolarizationactivated cation current and its role in rhythmic oscillation in thalamic relay neurons. J Physiol (Lond) 431:291-318.

McCormick DA, Pape HC (1990b) Noradrenergic and serotonergic modulation of a hyperpolarization-activated cation current in thalamic relay neurons. J Physiol (Lond) 431:319-342. 
McCormick DA, Wang Z (1991) Serotonin and noradrenaline excite GABAergic neurones of the guinea pig and cat thalamic reticular nucleus. J Physiol (Lond) 442:235-255.

Mitrofanis J (1994) Development of the thalamic reticular nucleus in Ferrets with special reference to the perigeniculate and perireticular cell groups. Eur J Neurosci 6:253-263.

Montero VM (1989a) The GABA-immunoreactive neurons in the interlaminar regions of the cat lateral geniculate nucleus: light and electron microscopic observations. Exp Brain Res 75:497-512.

Montero VM (1989b) Ultrastructural identification of synaptic terminals from cortical axons and from collateral axons of geniculo-cortical relay cells in the perigeniculate nucleus of the cat. Exp Brain Res 75:65-72.

Montero VM (1991) A quantitative study of synaptic contacts on interneurons and relay cells of the cat lateral geniculate nucleus. Exp Brain Res 86:257-270.

Montero VM, Singer W (1984) Ultrastructure and synaptic relations of neural elements containing glutamic acid decarboxylase (GAD) in the perigeniculate nucleus of the cat: a light and electron microscopic immunocytochemical study. Exp Brain Res 56:115-125.

Montero VM, Zempel J (1986) The proportion and size of GABAimmunoreactive neurons in the magnocellular and parvocellular layers of the lateral geniculate nucleus of the rhesus monkey. Exp Brain Res 62:215-223.

Mulle C, Madariaga A, Deschênes M (1986) Morphology and electrophysiological properties of reticularis thalami neurons in cat: in vivo study of a thalamic pacemaker. J Neurosci 6:2134-2145.

Norton TT, Godwin DW (1992) Inhibitory GABAergic control of visual signals at the lateral geniculate nucleus. Prog Brain Res 90:193-217.

O'Leary JL (1940) A structural analysis of the lateral geniculate nucleus of the cat. J Comp Neurol 73:405-430.

Pape HC, McCormick DA (1995) Electrophysiological and pharmacological properties of interneurons in the cat dorsal lateral geniculate nucleus. Neuroscience 68:1105-1125.

Sanchez-Vives MV, Bal T, McCormick DA (1995) Properties of GABAergic inhibition in the ferret LGNd contributing to the generation of synchronized oscillations. Soc Neurosci Abstr 21:11.
Sanderson KJ (1971) The projection of the visual field to the lateral geniculate and medial interlaminar nuclei in the cat. J Comp Neurol 143:101-118.

Sanderson KJ (1974) Lamination of the dorsal lateral geniculate nucleus in carnivores of the weasel (Mustelidae) raccoon (Procyonidae) and fox (Canidae) families. J Comp Neurol 153:239-266.

Schwartz ML, Meineke DL (1992) Early expression of GABA-containing neurons in the prefrontal and visual cortices of rhesus monkeys. Cereb Cortex 2:16-37.

So YT, Shapley R (1981) Spatial tuning of cells in and around lateral geniculate nucleus of the cat: $\mathrm{X}$ and $\mathrm{Y}$ relay cells and perigeniculate interneurons. J Neurophysiol 45:107-120.

Soltesz I, Crunelli V (1992) A role for low-frequency rhythmic synaptic potentials in the synchronization of cat thalamocortical cells. J Physiol (Lond) 457:257-276.

Soltesz I, Lightowler S, Leresche N, Jassik-Gerschenfeld D, Pollard CE, Crunelli V (1991) Two inward currents and the transformation of low frequency oscillations of rat and cat thalamocortical cells. J Physiol (Lond) 441:175-197.

Stichel CC, Singer W, Heizmann CW (1988) Light and electron microscopic immunocytochemical localization of parvalbumin in the dorsal lateral geniculate nucleus of the cat: evidence for coexistence with GABA. J Comp Neurol 268:29-37.

Stryker MP, Zahs KR (1983) On and Off sublaminae in the lateral geniculate nucleus of the ferret. J Neurosci 3:1943-1951.

Szentágothai J (1972) Lateral geniculate body structure and eye movement. Bibl Ophthalmol 82:178-188.

Uhlrich DJ, Cucchiaro JB, Humphrey AL, Sherman SM (1991) Morphology and axonal projection patterns of individual neurons in the cat perigeniculate nucleus. J Neurophysiol 65:1528-1541.

von Krosigk M, Bal T, McCormick DA (1993) Cellular mechanisms of a synchronized oscillation in the thalamus. Science 261:361-364.

Xue JT, Carney T, Ramoa AS, Freeman RD (1988) Binocular interaction in the perigeniculate nucleus of the cat. Exp Brain Res 69:497-508. 